\title{
Insiders Dissected: New Foundations and a Systematisation of the Research on Insiders
}

\author{
EPHRAIM ZIMMER, Technical University of Darmstadt, Germany \\ CHRISTIAN BURKERT and HANNES FEDERRATH, Universität Hamburg, Germany
}

\begin{abstract}
The insider threat is often cited as one of the most challenging threats for security practitioners. Even though this topic is receiving considerable attention, two main problems remain unsolved. First, research on insider threats is focusing on many different insiders without being able to actually identify and consistently entitle the key aspects of the insiders. As a result, this research can neither be identified by practitioners as being relevant for their real-world insider problems, nor can it be compared with other research targeting the same insider aspects. Second, a clear understanding of insiders is vital for analysing, which insider properties are responsible for the peculiarity of insider threats. In this article, a systematic approach to dissect the defining aspects of insiders is proposed, which includes specific allocatable insider characteristics. Additionally, the insider characteristics are extended toward insider types, which establish universal and unambiguous names for different insiders and which are related with each other to form a new and simple insider taxonomy. The new foundations on insiders allow the comparison of different insider research in a structured manner. Furthermore, the new approach facilitates the identification of specific features of insider threats in future work.
\end{abstract}

CCS Concepts: • Security and privacy $\rightarrow$ Human and societal aspects of security and privacy; Formal methods and theory of security; Security services; • Social and professional topics $\rightarrow$ User characteristics;

Additional Key Words and Phrases: Insider definition, insider type, insider modelling, insider taxonomy, insider ontology, research systematisation

ACM Reference format:

Ephraim Zimmer, Christian Burkert, and Hannes Federrath. 2021. Insiders Dissected: New Foundations and a Systematisation of the Research on Insiders. Digit. Threat.: Res. Pract. 3, 1, Article 2 (October 2021), 35 pages.

https://doi.org/10.1145/3473674

\section{INTRODUCTION}

The insider problem is probably as old as mankind itself. It is known from ancient tradition and poems already, that insiders posed special threats, which stand out from other threats. Take the example of the Trojan Horse, where the mythology says, that Greek warriors were hiding inside a wooden horse, which got pulled into the city of Troy. During the night, the warriors climbed out of the horse, opened the doors of Troy from the inside and with that, the Greek army was able to enter the city and defeat their enemies. However, as of today, the problem of insider threats seems far from being solved. This most probably is not due to the fact that insiders are adapting their techniques and we are seeing an arm's race with new and innovative mitigation techniques.

This paper is part of the first authors $\mathrm{PhD}$ thesis available in German at https://ediss.sub.uni-hamburg.de/handle/ediss/8860.

Authors' addresses: E. Zimmer, Technical University of Darmstadt, Hochschulstraße 10, Darmstadt, Hessen, Germany, 64289; email: zimmer@privacy-trust.tu-darmstadt.de; C. Burkert and H. Federrath, Universität Hamburg, Vogt-Kölln-Str. 30, Hamburg, Hamburg, Germany, 22527; emails: christian.burkert@uni-hamburg.de, hannes.federrath@unihamburg.de.

Permission to make digital or hard copies of all or part of this work for personal or classroom use is granted without fee provided that copies are not made or distributed for profit or commercial advantage and that copies bear this notice and the full citation on the first page. Copyrights for components of this work owned by others than ACM must be honored. Abstracting with credit is permitted. To copy otherwise, or republish, to post on servers or to redistribute to lists, requires prior specific permission and/or a fee. Request permissions from permissions@acm.org.

(C) 2021 Association for Computing Machinery.

2576-5337/2021/10-ART2 \$15.00

https://doi.org/10.1145/3473674 
Insider incidents have not changed much over time. What is more pressing is that researchers and practitioners cannot yet rely on thorough basic foundations of insiders and a systematisation of their distinct properties, which would help in structuring the research area on insiders as well as consolidate the knowledge and understanding of insider threats. One indication for that is the large number of insider definitions that have been proposed in the past and which often highlight varying aspects of an insider, e.g., References [3, 8, 17, 45, 48, 63], just to name a few of those that will be seen throughout this article. Another indication is the observation that many insider descriptions are even heavily debated, if they still belong to the group of insiders or must be considered as outsiders. The most prominent example is the one of a so called Masquerader [52, 53], to which the chosen example of the Trojan Horse might be attributed as well. ${ }^{1}$ Can the Greek warriors be seen as insiders, or as outsiders, or as both? Even though they were able to open the doors of Troy from the inside, just like any other citizen of Troy could have done alike, the warriors would not be put on the same level of insiderness as every other citizen of Troy.

In this article, we focus on the understanding and systematisation of insiders. While insider threats naturally are the broader context for our work, assessing and systematising insider threats constitutes more effort and needs to draw on the new foundations we will lay out in this article. ${ }^{2}$ We aim at the discovery of insights into the characteristics of insiders, which are of fundamental importance. This addresses the research question on what exactly is defining an insider and which different types of insiders can be derived as well as associated and dissociated from one another? Additionally, empowered by these insights and the understanding of insider characteristics, we are able to propose a simple yet universally applicable insider taxonomy, which not only shows the relations between different insider types, but also allows the structuring of the insider research field. The main contributions can be summarised as follows:

- Starting from a literature review, the most important aspects regarding a holistic and unambiguous view on insiders are identified.

- With a fundamental observation, insiders are dissected into five defining insider characteristics and their allocation is explained in detail.

- With these findings, a typecasting of insiders is proposed, which allows the separation as well as the combination of insider types. Furthermore, these insider types allow a unique and unambiguous description of different insiders for the first time.

- In an analogy of-and as a preparation for-threat modelling, insider modelling is introduced, which allows the identification of a person's insider characteristics in a methodologically sound and comprehensible way.

- Last, the developed insider types are put into relation with each other, allowing the deduction of a simple insider taxonomy. This taxonomy facilitates the systematisation of the existing and future literature on insiders as well as real-world insider scenarios.

The remainder of this article is structured as follows: Section 2 provides references to related work, which proposes several different insider definitions, and which attempts to systematise insiders. Section 3 puts the focus on specific characteristics, which describe the actual insiderness of an individual. With this, the typecasting of insiders is carried out in Section 4. A methodology for modelling insiders is proposed in Section 5, which aligns to the developed insider types. A new insider taxonomy is proposed in Section 6, while implications of the proposed new foundations on insiders for researchers and practitioners are highlighted in Section 7. The article closes with a conclusion and an outlook in Section 8.

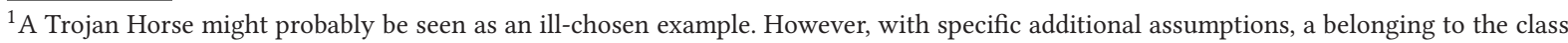
of insiders as well as to the case of a Masquerader can be argued. It also can justifyably be argued against this statement, which makes this example a good example for a debate.

${ }^{2}$ We will come back to this separation between insiders and insider threats, especially the implications of our work on the research on insider threats in Section 7.1.
} 


\section{RELATED WORK}

There are numerous descriptions, characterisations and definitions of insiders in the literature, which already have been tried to be structured with the help of ontologies and taxonomies. In this section, some of those insider definitions that will be referred to throughout this article, as well as efforts to systematise insiders and insider scenarios are described.

\subsection{Existing Insider Definitions}

Anderson [3] was one of the first to describe the threats, which arise from insider attackers. He defines insiders as individuals, who are normally authorised to use a computer system or a specific resource on that computer system. Neumann [45] assumes that "relative to a particular computational framework, insiders are users who have been authenticated to operate within that framework." The authorised privileges granted during authentication are used by the author to qualify these insiders, which constitutes a very early notion about different levels of insiderness. Wood [63] characterises insiders using the attributes access, knowledge, privileges, skills, risks, tactics, motivation, and process. Einwechter [17] is defining insiders in the domain of an organisational network. For his definition, he draws on the three characteristics trust, authorisation, and knowledge. According to the author, an insider is "someone who has been entrusted with authorised access to the network [...] to fulfil their obligations to the victim organization. Furthermore, they often have a substantial amount of knowledge about the network architecture, including where their targeted files or systems are located." Insiders defined by Patzakis [48] are "rogue employees and other trusted individuals." Brackney and Anderson [8] label an "already trusted person with access to sensitive information and information systems" or "[s]omeone with access, privileges, or knowledge of information systems or services" as an insider. Butts et al. [9] describe an insider as "[a]ny individual who has been granted any level of trust in an information system." Pfleeger [49] provides examples and scenarios of various insiders, e. g., a member or a former member of a host institution, someone with a formal or informal business relationship, anyone authorised to perform certain activities, or someone duped or coerced by an outsider to perform actions. Hunker and Probst [25] provide an overview of different insider definitions and argue that the actual problem is the so called real real insider: "an individual deeply embedded in an organization, highly trusted, and in a position to do great damage if so inclined (e. g., a high-level executive, or a systems administrator)." They additionally draw attention to the insider attributes authorisation, authentication, trust, consequences, and technical expertise. The CERT Guide to Insider Threats pictures "a current or former employee, contractor, or business partner who has or had authorized access to an organization's network, system, or data" [10] as insider. Several years later, an updated insider definition is provided in order to generalise its scope: "[A]n individual who has or had authorized access to an organization's assets" [14].

There are many other interpretations of the term insider in the literature, for instance in $[4-6,8,9,13,17$, $30,52,55]$. Most definitions of insiders put their focus on different characteristics and have different underlying assumptions about the distinction between an insider and other individuals. The large number indicates the high variety in the nature of insiders and the high complexity when it comes to the creation of a holistic understanding of insiders. All mentioned insider definitions as well as additional ones from the existing literature are systematised in Section 5.3 with the help of the new foundations, which are provided by this article.

\subsection{Insider Ontologies and Taxonomies}

In the process of discussing computer security auditing and surveillance capabilities of an organisation, Anderson [3] provides a small taxonomy by classifying different insiders into the four categories external ${ }^{3}$ penetrator,

\footnotetext{
${ }^{3}$ The terminology is misleading at this point. The author does not refer exclusively to an outsider, i. e., someone who is not part of the organisation.
} 
masquerader, legitimate user, and clandestine user, each specified by their access to an information system as well as their access to a resource within that information system. In almost the same way, Cole and Ring [12] propose four categories of insider threats based on the level of access as well, named (elevated) pure insider, insider associate, insider affiliate, and outside affiliate. The categorisation and naming of different insiders is a smart way of acknowledging different insider aspects, which have different effects when being utilised in malicious activities. However, this attempt does not pay attention to other important insider aspects and additionally falls short in explaining in more detail and depth the insider aspects, that set the four categories apart. Neumann [45] attempts to classify insiders by delimiting them from outsiders and concludes that insiders can only be defined according to a relative frame of reference, like trust, privileges or referenced data. According to the author, an outsider who gains access to a system by successfully penetrating its boundaries, becomes an insider from a mechanistic point of view, although having potentially less knowledge of the environment compared to a real insider. The frame of reference is a very important aspect, which will be picked up in Section 5. Additionally, Neumann [45] already explains the difference between two different types of insiders. One specified by the access to a system, and the other one by its knowledge of the environment. These insider aspects will be drawn upon and extended in Section 3 and Section 4. Tuglular [60] presents an insider computer misuse incident scheme, which is supposed to support the categorisation of insider incidents by identifying certain aspects of the incident. The scheme includes the three dimensions incident, response, and consequences with several sub-dimensions each. Very similar and detailed branching ontologies focus on insider threat indicators to systematise insider incidents. Advocates are Magklaras and Furnell [38], who propose an insider threat predition tool, with the toplevel dimensions system role, reason of misuse, and system consequences. Likewise, Costa et al. [15] refer to the top-level dimensions actor, action, asset, event, and information. And Greitzer et al. [20] draw on individual or organisational factors, a person or organisation as actors, and malicious or non-malicious intentions, and again several sub-dimensions. Even though all authors focus on the systematisation of insider threats rather than on the systematisation of the insider aspects that potentially have effects on insider threats, the schemes demonstrate attempts to create a more detailed and deeper understanding by dissecting the problem at hand. A very similar but differently focused approach will be presented in this article, which aims at dissecting insider aspects to understand the whole and true nature of insiders, and to allow a systematisation of the field of insider research and relate it to real-world scenarios. With that, the new foundations of insiders proposed in this article can be considered as an orthogonal complementation of this related work. Wood [63] describes an adversary model of a malicious insider, which can be implemented for simulation and further analysis. The author puts insider threats into focus and provides a set of aspects, which need to be included and specifically instantiated for an adversary model. In Section 5, this idea is adopted, formalised, and tailored toward insiders and their insiderness. Pfleeger et al. [50] present a framework, which helps identifying similarities and differences between past insider incidents and so support creating clusters of malicious insider activities for a specific organisation. The proposed framework consists of 10 questions covering the aspects organisation, individual, information technology, and environment. One set of answers defines a specific insider threat. This approach attempts to formalise the process of insider threat classification, which will be the focus of Section 5 as well.

Many of the mentioned systematisation attempts are focusing on the classification of insider threats, rather than on pure insider aspects related to certain threats. With that, the classification and systematisation mixes insider aspects with threat-specific aspects and as a result, does not facilitate analyses and insights of the role of insider aspects in certain scenarios. The following sections of this article try to overcome this gap by developing a simple ontology of insiders including an insider taxonomy.

\section{INSIDER CHARACTERISTICS}

Many characteristics have been suggested for describing an insider. For example, access to a domain [27, 32, 36, $48]$, an insider's intention [2, 7, 30, 44], or trust by authorities of the domain $[9,13,48]$. In reality, however, these 
suggestions, on the one hand, only depict partial aspects of an insider, as will be demonstrated in more detail in Section 5.3. On the other hand, not all proposed characteristics in the literature are actually suitable for defining an insider. The key observation on which aspects in general are defining an insider and what sets them apart from non-defining insider characteristics is the following: Insider characteristics can only be provided, granted, or are controlled by a specific domain or by authorities of that domain ${ }^{4}$ either deliberately or inadvertently. One can see that the domain of an insider constitutes an important area of reference. Examples of domains, which can also be referred to throughout this article, are organisations, information systems, computer networks, software or hardware products, or security mechanisms.

Another key observation is the one that the distinction between and insider and an outsider is not binary. There evidently exists a graduation in the distinction between an insider and an outsider, which in the literature has been named insiderness [6]. A good example is the case of the already mentioned masquerader, as highlighted by the Committee on Information Systems Trustworthiness [13]: "It is equally unclear whether a traditional spy or saboteur, operating form the inside at the behest of an outside organization, is an insider, an outsider, or yet a third class of entity." Bishop et al. [5] observed this non-binary distinction already, but did not explain its roots, its implications, and its resolution.

For a qualified and gradual description of an individual's insiderness with respect to a specific domain, the following unrestrictedly important characteristics are identified, which have to be provided to the individual by that domain. In practice, depending on the domain, its context, and the focus of the defining party, all or a subset of characteristics might be chosen and weighted differently (see Section 5). Introducing the insider characteristics to a greater degree as variables with the ability of being instantiated with certain qualified values goes beyond the attempts of previous research. It enables a more fine-grained characterisation in contrast of a definition by a simple static choice of these characteristics.

- Credentials ( $\mathrm{Cr}$ ), sometimes also referred to as Authentication, defines a membership relation by describing the legitimacy of the possession of a token, which can be used to authenticate oneself to a domain (see, e.g., References [2, 3, 25, 37, 54]). Credentials can be possessed legitimately, when deliberately granted to an individual by the domain, or illegitimately, either when acquired by means of a preceded attack, or when mistakenly given to an individual. By definition, an individual does not possess any Credentials when there is no way of successful authentication. ${ }^{5}$ In short, the concrete value of this characteristic can be one of the elements no, stolen, or legitimate.

- Knowledge $(\mathrm{Kn})$ refers to the degree of insight into a domain (see, e.g., References [8, 25, 29, 37, 45, 63]). It describes this kind of knowledge, that can only be provided by the domain. Examples are knowledge about assets or the internal IT infrastructure. The concrete degree of Knowledge possessed by an individual can be approximated by discrete values like negligible, low, middle, or high. It is highly domain specific, what constitutes high or low knowledge and there might be a huge difference between the knowledge about many but unimportant and the knowledge about a few but very important insights of a domain. This often so called insider knowledge is to be treated separately from the specific values of the characteristic Credentials, like passwords, which are called knowledge as well.

- Privileges (Pr), sometimes also called Access or Authorisation refers to the degree of enforceable and verifiable rights of interaction with a domain (see, e.g., References [3, 6, 25, 45, 56, 63]). It is very often directly connected to the characteristic Credentials, since the process of authentication via credentials usually provides a set of related privileges to an individual. Examples of Privileges are read and modify rights of filesystems, or the right to access and use assets. An assertion can be done by the values negligible, low, middle, or high. The degree of privileges heavily depends on the objects the individual is allowed to interact with and their value.

\footnotetext{
${ }^{4}$ For brevity and if not stated otherwise, we use the term domain to include authorities of the domain as well.

${ }^{5}$ This includes the possession of invalid or wrong Credentials.
} 
The main difference between Credentials, which defines a membership relation to a domain, and Privileges, which qualifies this membership relation, lies in the point of view of the domain. With an organisation as domain, a valid key card to access the building might constitute the Credentials of an insider. This key card is used by the insider to identify himself to the domain and allows the domain to verify the membership. Additionally provided access token, e.g., hardware keys to access rooms inside the building, or usernames and passwords to login to computer systems, can then be considered as Privileges of the insider. The usage of access token, which belong to other insiders, does not change the identity of the insider with respect to the domain. Considering the computer systems as the domain, however, the usernames and passwords are becoming the Credentials of the insider, and the Privileges are determined by the access control mechanisms of the computer systems. The usage of usernames and passwords from other insiders simultaneously changes the identity of the insider with respect to the domain. This example highlights the need to examine Credentials and Privileges separately and independently from each other.

- Trust (Tr), or to be more precise Individual Trust, describes the degree of faith of a domain put into an individual to act truly, credibly, and honestly (see, e.g., References [9, 13, 25, 37, 48]). More formally, it can be described as the probability that members of a domain are willing to deviate from policies and protocols when interacting with that individual. The concrete degree of Trust assigned to an individual is highly relationship dependent. Possible discrete values are negligible, low, middle, or high. During the estimation of its degree, influencing factors like a person's position, seniority, status, rank, or presentable experience of individuals need to be taken into account.

- Uncertainty (Un), or in other words Structural Trust, is defined as the deliberate or structural absence of assurance mechanisms like monitoring, verification, or controlling. With a high degree of Uncertainty, an individual can conduct activities without the domain being able to reproduce the actions during the process or afterwards. So in general, the allowance or tolerance of an individual's actions in the absence of security and monitoring mechanisms can be measured as Uncertainty. ${ }^{6}$ The concrete degree of Uncertainty is highly domain specific and can be expressed by the values negligible, low, middle, or high.

Obviously, there are many more characteristics than the ones explained previously, which can be used to describe an insider. However, such additional characteristics, for example the resources or the capabilities, do not have an influence on the insiderness of an individual. Outsiders can have high levels of such characteristics alike without becoming insiders. Therefore, such characteristics will be ignored throughout this article. They certainly are of great importance for the definition and characterisation of an insider threat, but this work is solely focusing on the characterisation of an insider and with that tries to lay out basic foundations for the research on insider threats in future work. See Section 7.1 for more details on the reasoning behind this focus.

\section{About the intention of an insider}

Research on insiders is often taking the intention or motivation of an insider into account $[2,7,30,36,44,48,61$, 64]. The intention can be divided into the three levels of intentionally malicious, accidental, which is equal to no intention, or intentionally good-natured. Each action of an insider is motivated accordingly without exception. Thus, the impression might arise that the intention needs to be considered as well when characterising an insider. However and according to our previous statement, the intention, like other additional characteristics of an individual, does not influence the individuals' insiderness. In this article, we are neither focusing on the intention of insiders nor are we implicitly assuming any specific intention of insiders, e.g., the malicious insider. The following sections apply to all three levels of intention. In particular, a certain insider stays exactly the same insider, no matter if the intention behind his actions are malicious or non-malicious.

\footnotetext{
${ }^{6}$ This insider characteristic is not intuitive and might be hard to grasp. The Example 5.3 on page 12 tries to illustrate its meaning in a realistic scenario.
}

Digital Threats: Research and Practice, Vol. 3, No. 1, Article 2. Publication date: October 2021. 


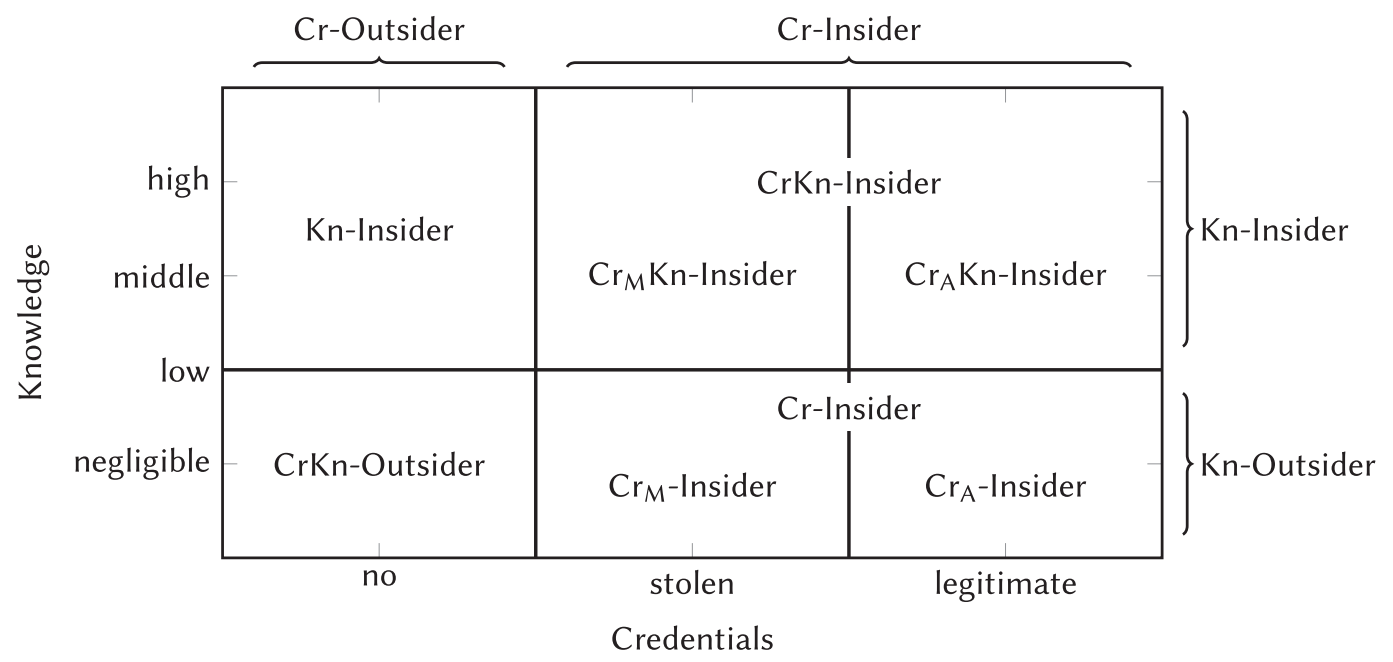

Fig. 1. The insider types, which evolve by combining the different values of Credentials and Knowledge.

On the contrary, the distinction between the different levels of intention is of great importance when dealing with insider threats [25]. Different intentions eventually must lead to different responses and mitigation techniques when it comes to insider threats $[23,50]$. Consequently, this characteristic needs to be considered in future work, when the new foundations of this article are applied to the research and systematisation of insider threats (see Section 7.1).

\section{INSIDER TYPES}

Various instances of insider characterisations can be categorised to specific insider types. Some of these types have already been mentioned in the literature (cf. Section 2.2), but none have been derived from specific characteristics, introduced as insider types, or associated and dissociated to other insider types. This proposed approach paves the way to systematically characterise insiders and derive dependencies between different insider types (see Section 5 and Section 6). Further, common threat aspects can be identified, which are uniquely shared by the same type of insiders and divert between different ones. These considerations together form a new foundation for the development of specific countermeasures and mitigation techniques against insider threats.

\subsection{Basic Insider and Outsider Types}

The characteristics provided by a domain, as point out and described in Section 3, alone make a difference to the distinction between an insider and an outsider. They further describe how deeply an individual is embedded into a domain, which is constituting an individuals insiderness. So the following basic insider types are solely based on these characteristics. An important observation is that every such characteristic defines an insider and an outsider in its own independent dimension. An illustration is given by Figure 1.

One insider aspect of an individual is the Knowledge provided by a domain. An individual with low, middle or high Knowledge about a domain can be considered an insider and an individual with negligible Knowledge can be considered an outsider with respect to the insight into a domain. This distinction can be made independently from the insiderness qualified by other provided characteristics, e.g., no matter if the individual is associated to the inside of a domain by means of valid Credentials or not. Therefore and to avoid terminological confusion, the basic insider and outsider types Knowledge-Insider (Kn-Insider) and Knowledge-Outsider (Kn-Outsider) are introduced. Similarly and independently from describing an individual as Kn-Insider or Kn-Outsider, the individual can be 
considered a different kind of insider, when having valid credentials and the individual can be described as a different kind of outsider, when having no valid credentials. This dimension describes an individual with respect to its locational relation to the domain, ignoring the insight into the domain. These individuals are described as Credentials-Insider (Cr-Insider) and Credentials-Outsider (Cr-Outsider). Cr-Insider can be further divided into those, who legitimately own Credentials and those having stolen the Credentials from other Cr-Insider. The former cases are named Credentials-Associate (CrA-Insider) and the latter ones Credentials-Masquerader (CrM-Insider). The same observations hold for the basic insider types Privileges-Insider (Pr-Insider), Trust-Insider (Tr-Insider) und Uncertainty-Insider (Un-Insider) with the qualitative characteristic values of low, middle, or high respectively as well as for the corresponding basic outsider types with the characteristic value negligible.

\subsection{Insider Type Combinations}

Anderson [3] introduces four different kinds of insiders and names them "External Penetrator," "Masquerader," "Legitimate User," and "Clandestine User" to make them distinguishable from the pervasively used term "Insider." He mainly bases the definitions on the two characteristics Credentials and Privileges. Hunker and Probst [25] define an insider mainly based on these characteristics as well and name their insider "real real insider". Furthermore, especially the catchy term "Masquerader" has been picked up by other authors and stripped of some characteristics, e.g., by Lundin and Jonsson [36] or Bowen et al. [7]. Other occurring terms are "Traitor" [7] and "Errant Insider" [30], leading to a mixture of names for different or even the same kinds of insiders. This mixture together with our observation, that an individual always constitutes a combination of the basic insider and outsider types identified in Section 4.1 and all of these types can be combined due to their independence, leads to the conclusion, that all former approaches of establishing terms for different kinds of insiders do not scale. Instead, there is a need for a universal naming convention based on the identified basic insider and outsider types. To retain the unambiguity of specific combinations of insider and outsider types and allow the ability to do like-to-like comparisons, the following naming convention is proposed.

4.2.1 Universal Naming Convention. Each basic insider and outsider type has been abbreviated with the first letter of the corresponding underlying characteristic. With these abbreviations together with the commitment to first list combined insider abbreviations in their alphabetical order followed by the list of combined outsider abbreviations in their alphabetical order, each combination of basic insider and outsider types receives a comprehensive unique name. For example, an individual, who is a Knowledge-Insider, a Credentials-Outsider, and an Trust-Insider, should be named KnTr-Insider-Cr-Outsider. With the underlying assumption, that not listed insider types equal outsider types, the list of trailing outsider types can be cut off, in cases when their mentioning is not important, which allows even compacter names. In this way, the above example constitutes an $\mathrm{KnTr}$-Insider.

This method allows a precise description of the attempts to name different insider types in the existing literature. Table 1 shows the respective insider types based on the new naming convention. More details, especially the corresponding insider descriptions and the assumed insider domain, can be found in Section 5.3 and Appendix A.

4.2.2 Example Combination of Knowledge and Credentials Types. The basic insider types Kn-Insider and CrInsider derived from the provided characteristics Knowledge and Credentials are probably the most intuitive types when dealing with an insider. The combination of those two insider types, as illustrated in Figure 1, creates insider types, which embrace scenarios of highly practical relevance and which in the past have been difficult to grasp. For this reason, their combinations are explained in more detail as an example of the new naming convention.

The CrKn-Outsider represents what intuitively is meant by a non-insider. It describes an individual, who does not have any or at most very low insight into a domain and no direct association to the inside of a domain. So it describes any individual, who is not falling into one of the other insider types. The CrKn-Insider includes what has informally and statically been described by Einwechter [17] and Mathew et al. [40] as an insider. It describes 
Table 1. Precise description of self-given names in the literature Precise Description of Different or Identical Self-given Names in the Literature with the Help of the Identified Insider and Outsider Types

\begin{tabular}{rll}
\hline Reference & self-given name & precise insider-/outsider type \\
\hline Anderson [3] & External Penetrator & $\mathrm{Cr}$-Outsider \\
& Masquerader & $\mathrm{Cr}_{M}$ Pr-Insider \\
& Legitimate User & $\mathrm{Cr}_{\mathrm{A}}$ Pr-Insider \\
& Clandestine User & $\mathrm{Cr}_{\mathrm{A}}$ PrUn-Insider \\
\hline Lundin and Jonsson [36] & Masquerader & $\mathrm{Cr}_{M}$-Insider \\
\hline Bowen et al. [7] & Masquerader & $\mathrm{Cr}_{M}$ Kn-Insider \\
& Traitor & $\mathrm{Cr}_{\mathrm{A}}$ Kn-Insider \\
\hline Hunker and Probst [25] & Real Real Insider & $\mathrm{Cr}_{\mathrm{A}}$ PrTr-Insider \\
\hline Kaplan et al. [30] & Errant Insider & $\mathrm{Kn}$-Outsider \\
\hline
\end{tabular}

For more details cf. Section 5.3 and Appx A.

an individual, who has insider knowledge about a domain and additionally has an unmediated association to the inside of this domain. These two types clearly align to the general line of argumentation and to the underlying intuition assumed in the existing literature when dealing with an insider.

The Cr-Insider-Kn-Outsider describes an individual with access to the internal of a domain due to the possession of valid credentials, but nothing more, especially with only very low insight into the domain, if any. An example is a CrKn-Outsider, who succeeds in guessing valid credentials of a Cr-Insider. The problem to attribute the $\mathrm{Cr}$-Insider-Kn-Outsider either as an insider or as an outsider can now be solved by this distinction between insider types. The example shows that any Outsider with valid credentials, who is able to perform actions inside a domain, does not have to be considered as an outsider anymore, but can now be considered as a specific type of insider, which additionally can be separated from any Insider with valid credentials.

Similarly, the Kn-Insider-Cr-Outsider represents unintuitive and debated corner cases as well. It illustrates an individual with no association to the inside of a domain, possibly not anymore, but with a certain degree of insider knowledge about the domain. Examples are ex-employees from the point of view of an organisation, an employee without credentials to an internal subsystem from the point of view of that subsystem, or a person who originally designed a domain, but is not in any way associated with the domain anymore. This insider type resolves a misconception when describing an insider, that an insider always is directly associated with the inside of a domain $[25,55,63]$, e.g., "The Insider attacks the [domain] from behind or inside a system's perimeter defenses" [63]. ${ }^{7}$

The $\mathrm{Cr}$-Insider types can additionally be divided into those individuals legitimately possessing valid Credentials and those illegitimately possessing valid Credentials (cf. Figure 1). The $\mathrm{Cr}_{A}$-Insider-Kn-Outsider describes an individual who legitimately owns valid credentials and who only is distinguishable from a $C r_{A} K n$-Insider by its lower degree of Knowledge about the domain. An example is a new employee who does not have clearance for knowing certain insights, who is not aware of internal conventions, or does not know about security policies and deployed monitoring techniques. The $\mathrm{Cr}_{M}$-Insider-Kn-Outsider is a Kn-Outsider, who happens to have acquired valid credentials, which have not been given to him by the domain deliberately. A case which is commonly referred to as masquerading [3] and controversially debated if it still belongs to the class of insiders or not [52, 53]. This debate can now be resolved. As soon as this individual acquires insider Knowledge about the domain, it can be describes as an $\mathrm{Cr}_{M} \mathrm{Kn}$-Insider.

\footnotetext{
${ }^{7}$ Refer to Appendix A.24 and A.40 for the statements of the other two references.
} 


\section{INSIDER MODELLING}

In this section, the process of Insider Modelling is introduced as a structured and dynamic way of describing the aspects of an insider for specific domains. In this respect, it facilitates the development of a consistent and comparable notion of insiders. It allows to emphasise specific insider aspects while at the same time does not neglect other more unimportant insider aspects for a specific domain. The goal is to stipulate an individual's insider type and qualify its insiderness.

Definition 1. An insider model describes the insiderness of an individual with respect to a specific domain. It consists of the following parts:

(1) An explicit denotation of the domain.

(2) A set of insider characteristics, which are important in the context of the domain.

(3) A domain specific semantic of the characteristic values for each characteristic included in the set of part 2. Such a semantic can be disregarded, as long as it is intuitive. ${ }^{8}$

(4) An instantiation of all characteristics in the set of part 2 presenting a characterisation of an individual.

The modelling part 1 is often not considered, when describing an insider [29-31, 44, 50, 64]. However, an insider for one domain does not have to be the same insider for another domain. The modelling parts 2 and 3 provide a specification of the domain mentioned in part 1 and set the context for which the specific characterisation of an individual in part 4 is applicable. Part 4 in conjunction with part 3 allows the derivation of specific insider types (cf. Section 4), that underlie the provided insider model. The following sections provide examples for the notation of insider models. Also, a formal methodology for analysing insider scenarios and definitions is introduced, which eventually is applied to a set of insider definitions from the existing literature.

\subsection{Example Insider Models}

The following remarks provide examples of insider models in the context of different scenarios. The focus remains on insider characteristics rather than on threat characteristics, even though they all deal with insider threats.

Example 5.1 (Employee). An employee gets into personal financial trouble and tries to get privileged access to a subsystem, which holds highly valuable assets of its organisation, to steal those assets, and finally to sell them. To successfully complete the plan and to remain undetected, the individual needs to increase its Knowledge and Privileges to deactivate or circumvent security and monitoring mechanisms.

Assuming the whole organisation of this scenario as domain and the employee as individual, who should be characterised, the set of important characteristics of an insider model would contain Knowledge, Credentials, Privileges, and Uncertainty. The insider model of this scenario can be summarised as follows:

\begin{tabular}{|l|}
\hline Domain: The whole organisation \\
\hline Insider Characteristics: \\
- Credentials: legitimate $\rightarrow \mathrm{Cr}_{\mathrm{A}}$-Insider \\
- Knowledge: low $\rightarrow \mathrm{Kn}$-Insider \\
- Privileges: low $\rightarrow$ Pr-Insider \\
- Uncertainty: negligible $\rightarrow$ Un-Outsider \\
Insider Type: $\mathrm{Cr}_{\mathrm{A}} \mathrm{KnPr}$-Insider
\end{tabular}

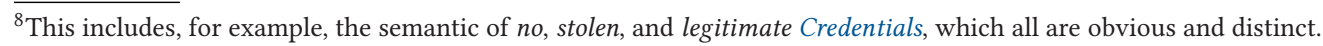


The individual is an employee, which means he legitimately owns valid credentials to act inside the perimeter of the domain. Thus, the individual is a case of a $\mathrm{Cr}_{\mathrm{A}}$-Insider. The level of Knowledge is not sufficient to know about existing security and monitoring mechanisms. Otherwise, the employee would not need to increase it. As an employee, however, the individual has a restricted degree of insight into the domain at the least, since he knows the location and the value of the assets. Thus, the individual is a case of a Kn-Insider. The level of Privileges is not sufficient to manipulate existing security and monitoring mechanisms. Otherwise, the employee would not need to increase it. But as an employee with valid credentials, the individual very likely has at least a restricted degree of Privileges. Nonetheless, with a default point of distinction for this characteristic, the individual is a Pr-Insider. The fact that security and monitoring mechanisms need to be manipulated by the employee to stay undetected sets the level of Uncertainty to negligible. Thus, the individual is a case of an Un-Outsider.

Changing the domain of this example to the subsystem, which holds the valuable assets, the insider model slightly changes. It can be summarised as follows:

\begin{tabular}{|l|}
\hline Domain: The subsystem holding valuable assets \\
\hline Insider Characteristics: \\
- Credentials: no $\rightarrow$ Cr-Outsider \\
- Knowledge: middle $\rightarrow$ Kn-Insider \\
- Privileges: negligible $\rightarrow$ Pr-Outsider \\
- Uncertainty: negligible $\rightarrow$ Un-Outsider \\
Insider Type: Kn-Insider
\end{tabular}

The security mechanisms, which need to be deactivated to be able to steal the highly valuable assets, include access control mechanisms for the domain. Thus, the individual is a case of a Cr-Outsider. The fact that the individual knows about the assets, their value, and how to get to them, the degree of Knowledge is middle or higher. Thus, the individual is a case of a Kn-Insider. The enforceable and verifiable rights of interaction with the domain are negligible. Otherwise, the individual would not need to get privileged access to the domain. Thus, the individual is a case of a Pr-Outsider. The security and monitoring mechanisms seem to protect not only the domain but also the highly valuable assets inside the domain. Thus, the level of Uncertainty is negligible, leading to a case of an Un-Outsider.

Example 5.2 (Police Officer). A beautiful young lady attracts the attention of a policeman on the beat when she exits her correctly parked car and leaves. The police officer does not think about the legal and ethical consequences of his next action and looks up the owner of that car via the numberplate for the purpose of learning the contact information of that lady.

A very similar case was revealed in October 2019 about employees of the Federal Bureau of Investigation [62]. With the car owner database as domain, the set of important characteristics of an insider model would contain Credentials, Knowledge, Privileges, and Uncertainty. The characteristics of this scenario can be summarised as follows:

\begin{tabular}{|l|}
\hline Domain: The car owner database \\
\hline Insider Characteristics: \\
- Credentials: legitimate $\rightarrow \mathrm{Cr}_{\mathrm{A}}$-Insider \\
- Knowledge: high $\rightarrow \mathrm{Kn}$-Insider \\
- Privileges: middle $\rightarrow$ Pr-Insider \\
- Uncertainty: middle $\rightarrow$ Un-Insider \\
\hline Insider Type: $\mathrm{Cr}_{\mathrm{A}} \mathrm{KnPrUn}-\mathrm{Insider}$ \\
\hline
\end{tabular}


The police officer legitimately owns valid credentials to act inside the perimeter of the police information system. Thus, the officer is a case of a $\mathrm{Cr}_{A}$-Insider. The degree of Knowledge must be above a threshold to be able to work with the police information system. Thus, the officer is a case of a Kn-Insider. He is allowed to send queries to the car owner database inside the police information system. So the level of Privileges is at least as high as to be the case of a Pr-Insider. The abuse of his access rights only becomes apparent due to the situational description, which shows no wrongdoing of the lady. The domain, however, does not have this background information, so the police officer is an Un-Insider.

Example 5.3 (Hospital Nurse). A hospital patient is entering a critical state and causes an emergency. A nurse in charge cannot reach any doctor and so decides to use the credentials of one of the doctors to login into the medical documents system of the hospital and to get insight into the medical documents of that patient. He finds out which medicine is allowed to stabilise the patient and rescues the patient.

A case analysis by Koppel et al. [33] of very similar cases shows, that this again is not a constructed scenario. Taking the medical documents system of the hospital as domain, the set of important characteristics of an insider model would contain Credentials, Knowledge, Privileges, and Uncertainty. The insider model of this example can be summarised as follows:

\begin{tabular}{|l|}
\hline Domain: The medical documents system \\
\hline Insider Characteristics: \\
- Credentials: stolen $\rightarrow \mathrm{Cr}_{M}$-Insider \\
- Knowledge: middle $\rightarrow \mathrm{Kn}$-Insider \\
- Privileges: middle $\rightarrow \mathrm{Pr}$-Insider \\
• Uncertainty: negligible $\rightarrow$ Un-Outsider \\
\hline Insider Type: $\mathrm{Cr}_{M} \mathrm{KnPr}$-Insider \\
\hline
\end{tabular}

The nurse somehow knows the credentials of one of the doctors, which effectively means he illegitimately got into their possession, even when they were given to him by the doctor. Thus, the nurse is a case of a $\mathrm{Cr}_{M}$-Insider. The degree of Knowledge must be middle or above to be able to work with the medical documents system of the hospital. Thus, the nurse is a case of a Kn-Insider. With the credentials of the doctor, the nurse is allowed to access and read medical documents. So the level of Privileges is at least middle, which leads to a Pr-Insider. Such an emergency case will be registered and documented in a hospital, so that the behaviour of the nurse will be detected after the return of the doctor at the latest. Thus, the Uncertainty is negligible and the nurse constitutes a Un-Outsider in its stolen role as a doctor.

\subsection{Methodology for Analysing Insider Scenarios and Descriptions}

To derive insider models from insider definitions and descriptions, this section provides a formal methodology, which is based on the Qualitative Content Analysis specified by Mayring [43]. This approach allows a consistent deduction of insider models out of existing insider definitions and scenarios. At the same time, this deduction becomes transparent, verifiable, and reproducible. Qualitative Content Analysis presents a rule-governed analysis procedure of texts and can be described as the "process of assigning categories to text passages as a qualitativeinterpretive act, following content-analytical rules" [43]. According to the author, it is a two-step approach. During the first step, categories will be named and described, which are derived, for example, inductively from the text at hand, or in a theory-driven deductive way. The second step assigns specific parts of the text to these categories with the help of a coding template. In this article, the methodology is based on a specific manifestation called Structuring-Deductive Category Assignment [43, Section 6.5]. The categories are ordered numerically and derived in a theory-driven way in advance. Step one has been conducted deductively in Section 3 already and 
Table 2. Numerical Order of the Insider Characteristic Values, which Are Introduced and Described in Section 3

\begin{tabular}{lccccccc}
\hline & -1 & 0 & 1 & 1,5 & 2 & 2,5 & 3 \\
\hline Credentials $(\mathrm{Cr})$ & no & not stated & - & - & stolen & stolen-legitimate & legitimate \\
Knowledge $(\mathrm{Kn})$ & negligible & not stated & low & low-middle & middle & low-high & high \\
Privileges $(\mathrm{Pr})$ & negligible & not stated & low & low - middle & middle & low - high & high \\
Trust $(\mathrm{Tr})$ & negligible & not stated & low & low-middle & middle & low-high & high \\
Uncertainty $(\mathrm{Un})$ & negligible & not stated & low & low-middle & middle & low-high & high \\
\hline
\end{tabular}

resulted in the categories of the five insider characteristics: Credentials (Cr), Knowledge (Kn), Privileges (Pr), Trust (Tr), and Uncertainty (Un). The numerical order within the categories is summarised in Table 2. It results from the concrete and discrete values of the insider characteristics, e.g., negligible, low, middle, and high, extended by the interim values not stated, low-middle, and low-high. The coding template for step two, which is necessary for deriving an insider model out of a description or scenario, is specified in Table 3. The minimal text part, which can be assigned to a category and which is also called a coding unit, refers the description of an insider at hand. The so-called context unit, meaning the kind of material, which can be drawn onto during the process of coding or interpretation, spans the whole work where the description of interest is embedded.

It is possible that the description of an insider matches several numerical values of one characteristic. In these cases, several insider types might be derived during the process of coding, resulting in several insider types in one insider model. An example for such an insider description, which includes several different insider and sometimes even outsider types, is the one from Butts et al. [9], which can be seen in Appendix A.17.

\subsection{Classification of Existing Insider Definitions}

The process of insider modelling can be applied to existing insider definitions, to classify them according to the underlying insider types. For this classification 85 insider definitions from 49 different scientific publications have been extracted and analysed. The publications were found by a combination of keywords, forward, and backward reference searching. One key finding of this analysis is, that often more than one insider type is described by an insider definition, due to a lack of detailed information about the specific values of insider characteristics. This leads to ambiguities when classifying a proposed insider definition. Additionally, the lack of a domain specification leads to different insider types and sometimes even pure outsider types when assuming different domains. Butts et al. [9], for example, define an insider as "[a]ny individual who has been granted any level of trust in an information system." Any level of Trust ranges from high to negligible Trust, which describes a TrInsider and a Tr-Outsider alike.

The insider models, which can be derived from the 85 analysed insider descriptions and definitions are listed in detail in Appendix A and the resulting insider types are summarised in Table 4. For clarity, all $\mathrm{Cr}_{\mathrm{A}}$-Insider and $\mathrm{Cr}_{M}$-Insider are counted together as $\mathrm{Cr}$-Insider. The table shows the broad diversity when it comes to insider definitions. However, the table also illustrates the focus, which is prevalent in the analysed existing literature. By far the most definitions that have been analysed, concentrate on a Cr-Insider, a Pr-Insider, and a CrPr-Insider. This might be due to the fact that these insider characteristics not only define the most intuitive and easiest describable insider types, but also are the most suitable subjects for technical mitigation strategies and most easy subjects for threat analysis. It must be noted, however, that the heavy inbalance might also derive from a bias in the keyword, forward, and backward reference search conducted for this study. To get a more holistic view on the landscape of insider research, the dataset of classified existing insider literature will be made publicly available for further extension and enhancement (see Section 7).

\section{INSIDER TAXONOMY}

The preceding sections developed representative basics and primitives, which describe insider types as well as their characteristics and applications in the form of insider models. These basics and primitives are important pieces of an insider ontology, which is described by Gruber [24] as the structuring and modelling of a specific 
Table 3. Coding Template for the Classification of Text Parts from Different Insider Descriptions to the Corresponding Numerical Value of the Insider Characteristics

\begin{tabular}{|c|c|c|c|}
\hline Value & Category & Coding Template & Anchor Example \\
\hline$\overline{-1}$ & $\mathrm{Cr}, \mathrm{Kn}, \mathrm{Pr}, \mathrm{Tr}, \mathrm{Un}$ & $\begin{array}{l}\text { This category is described as } \\
\text { non-existent. }\end{array}$ & $\begin{array}{l}\operatorname{Cr}(-1), \operatorname{Tr}(-1) \text { : "Outside affiliates are non-trusted outsiders who use } \\
\text { open access to gain access to an organization's resources [and have } \\
\text { no legitimate reason to access the building]" [12]; } \\
\text { Tr(-1): "Any individual who has been granted any level of trust in an } \\
\text { information system" [9] }\end{array}$ \\
\hline$\overline{0}$ & $\mathrm{Cr}, \mathrm{Kn}, \mathrm{Pr}, \mathrm{Tr}, \mathrm{Un}$ & $\begin{array}{l}\text { The category is not mentioned } \\
\text { and can neither be derived from } \\
\text { the coding unit nor from the } \\
\text { context unit. }\end{array}$ & $\begin{array}{l}\operatorname{Kn}(0), \operatorname{Tr}(0), \operatorname{Un}(0): \text { "An insider can be an employee, student, or other } \\
\text { member of a host institution that operates a computer system to } \\
\text { which the insider has legitimate access [...]" [49] }\end{array}$ \\
\hline 1 & $K n, P r, T r, U n$ & $\begin{array}{l}\text { The insider description indicates } \\
\text { a distinctly low value of this } \\
\text { category. }\end{array}$ & $\begin{array}{l}\text { Kn(1): The ex-employee has been discharged already during his } \\
\text { probation and thus only had the chance to learn about unimportant } \\
\text { processes of the organisation. }\end{array}$ \\
\hline$\overline{1,5}$ & $K n, P r, T r, U n$ & $\begin{array}{l}\text { The description of this category } \\
\text { suggests a numerical value } \\
\text { between } 1 \text { and } 2 \text {. }\end{array}$ & $\begin{array}{l}\text { Kn(1,5): "An insider is a database subject who has personal } \\
\text { knowledge of information stored in one or more fields marked } \\
\text { confidential" [40] }\end{array}$ \\
\hline$\overline{2}$ & $\overline{K n}, \bar{P} r, \overline{T r}, \overline{U n}-$ & $\begin{array}{l}\text { The description of this category } \\
\text { indicates a valid and accepted } \\
\text { membership to a domain, which } \\
\text { is based on a false identity. In } \\
\text { general, this indicates the usage } \\
\text { of stolen or faked authentication } \\
\text { tokens. } \\
\text { The insider description indicates - } \\
\text { a distinctly middle level of this } \\
\text { category. }\end{array}$ & $\begin{array}{l}\operatorname{Cr}(2) \text { : "A masquerader can be defined as a person, either external } \\
\text { or internal, who uses an account on the system for which he is not } \\
\text { authorized" [36] }\end{array}$ \\
\hline$\overline{2,5}$ & $\mathrm{Cr}, \mathrm{Kn}, \mathrm{Pr}, \mathrm{Tr}, \mathrm{Un}$ & $\begin{array}{l}\text { The description of this category } \\
\text { suggests a numerical value } \\
\text { between } 1 \text { and } 3 \text {. }\end{array}$ & $\begin{array}{l}\operatorname{Tr}(2,5) \text { : "A person with some sort of organizational status that causes } \\
\text { members of the organization to view requests or demands as being } \\
\text { authorized" [13] }\end{array}$ \\
\hline$\overline{3}$ & $\overline{K n}, \bar{P} r, \overline{T r}, \overline{U n}{ }^{-}$ & $\begin{array}{l}\text { The description of this category } \\
\text { indicates a legitimate membership } \\
\text { to a domain, which can plausibly } \\
\text { be proven to the domain as well as } \\
\text { to third parties. } \\
\text { The insider description indicates } \\
\text { a distinctly high level of this } \\
\text { category. }\end{array}$ & 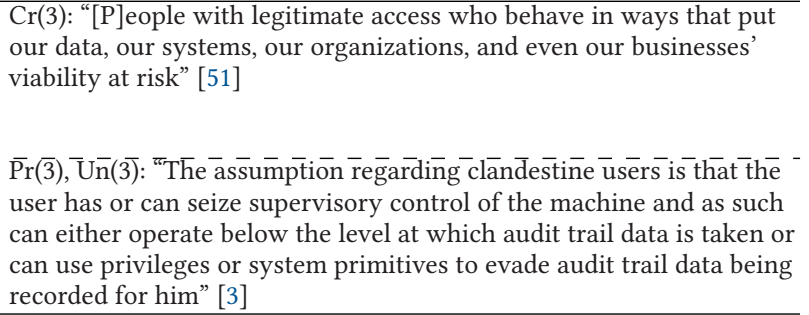 \\
\hline
\end{tabular}

area or discourse. The representative basics and primitives usually comprise classes, attributes of class elements as well as relations between these elements. Therewith, a taxonomy is an important part of such an ontology [19], which is defining the is $a$ relationship of class elements and so facilitates the actual classification [26]. In this section, the illustration and explanation of a simple insider taxonomy completes this insider ontology, so that relations between insider types are becoming apparent.

Each characteristic provided to an individual by a domain defines an insider type in its own independent dimension and each insider type can be combined (cf. Section 4). With this, a simple insider taxonomy can be developed, which maps the relationships between insider types. Each basic insider type is a true enhancement of its corresponding outsider type in terms of the degree of the underlying characteristic provided by a domain. For example, a Pr-Insider has the same privileges as a Pr-Outsider as well as additional privileges. Furthermore, a combination of basic insider types is an enhancement of all possible sub-combinations. The $\mathrm{Cr}_{\mathrm{A}} \mathrm{KnPr}$-Insider of the insider model according to Example 5.2 in Section 5, for example, possesses all properties and capabilities that are possessed by a $\mathrm{Cr}_{A} \mathrm{Kn}$-Insider, a $C r_{A} P r$-Insider, a $\mathrm{KnPr}$-Insider, a $C r_{A}$-Insider, a Kn-Insider, as well as a $\mathrm{Pr}$ Insider. Figure 2 shows these relationships and illustrates the proposed insider taxonomy. Again, for clarity, the $\mathrm{Cr}_{A}$-Insider and the $\mathrm{Cr}_{M}$-Insider types are not separated.

Digital Threats: Research and Practice, Vol. 3, No. 1, Article 2. Publication date: October 2021. 
Table 4. Classification of Existing Insider Definitions Based on the Underlying Insider Types

\begin{tabular}{rrl}
\hline Cr-Insider & $25.40 \%$ & {$[2,3,7,8,10,12,14,27-29,32,35-37,41,42,45,48-51,54,55,61]$} \\
Pr-Insider & $22.22 \%$ & {$[3,5,6,8,10,12-14,25,29,31,37,42,44,47,49-52,54-56,61]$} \\
CrPr-Insider & $15.87 \%$ & {$[2,3,10,12,13,18,28,30,34,41,45,49,59,61]$} \\
CrKn-Insider & $4.76 \%$ & {$[7,11,17,40,64]$} \\
Kn-Insider & $3.97 \%$ & {$[8,29,37,42,44]$} \\
PrTr-Insider & $3.17 \%$ & {$[8,21,22,34]$} \\
CrTr-Insider & $3.17 \%$ & {$[8,21,22,37]$} \\
Tr-Insider & $2.38 \%$ & {$[9,13,48]$} \\
KnPrTr-Insider & $2.38 \%$ & {$[16,46]$} \\
KnPr-Insider & $1.59 \%$ & {$[58,64]$} \\
CrPrUn-Insider & $1.59 \%$ & {$[3,39]$} \\
CrKnPr-Insider & $1.59 \%$ & {$[37,58]$} \\
CrPrTr-Insider & $1.59 \%$ & {$[4,25]$} \\
KnTr-Insider & $0.79 \%$ & {$[21]$} \\
CrKnPrUn-Insider & $0.79 \%$ & {$[11]$} \\
CrKnPrTr-Insider & $0.79 \%$ & {$[16]$} \\
KnPrTrUn-Insider & $0.79 \%$ & {$[18]$} \\
CrKnPrTrUn-Insider & $0.79 \%$ & {$[18]$} \\
\hline Cr-Outsider & $3.17 \%$ & {$[3,10,12,14]$} \\
Outsider & $1.59 \%$ & {$[30,49]$} \\
Tr-Outsider & $0.79 \%$ & {$[9]$} \\
Kn-Outsider & $0.79 \%$ & {$[30]$} \\
\hline
\end{tabular}

The percentages show the proportion of that insider type with respect to the identified insider types throughout all analysed publications.

With detailed and adequate insider models according to the instructions in Section 5, a domain can identify the part of the taxonomy accordingly, which is relevant for a specific insider model. In conjunction with the classification of existing insider definitions introduced in Section 5.3, those publications which correspond to an insider model at hand and which might provide valuable new knowledge can be identified in a structured manner. Staying with the example of a $\mathrm{Cr}_{A} \mathrm{KnPr}$-Insider, the publications of Spitzner [57] as well as Maasberg et al. [37] can be identified, whose insider definitions focus on this insider type as well. Spitzner [57], for example, proposes the utilisation of honeypots and specifically tailored decoy documents called honeytokens, to monitor and analyse the behaviour of insider attacker. Maasberg et al. [37] in turn put their focus on psychological indicators to detect insider threats. The authors show a relation between insider threats and the so called dark triad of personality traits. In addition to this facilitation of identifying publications, superordinate aspects of an insider type at hand can be found in publications, which include the $\mathrm{Cr}_{A} \mathrm{KnPr}$-Insider as sub-type. Reversely, subordinate aspects of an insider type can be found in publications, which focus on a sub insider type.

For all these proposals to work, it is of vital importance that the insider definitions and insider models chosen by authors match the actual context of suggested findings and mitigation techniques. This, however, does not always seem to be the case. One counter example is the already mentioned work of Spitzner [57], who is focusing on the insider threats of a $\mathrm{Cr}_{A} \mathrm{KnPr}$-Insider according to his insider definition, but the proposed mitigation technique of decoy documents in fact does focus on the insider threats of a PrUn-Insider. As a consequence, in future work, security mechanisms and mitigation techniques, which are used to counter the threats of insiders must be analysed and systematised according to the insider taxonomy. This will allow to identify and implement precisely fitting security mechanisms and mitigation techniques, which target the threats of specific insider types. Furthermore, it will allow to compare competing security mechanisms and combine those ones, which effectively 


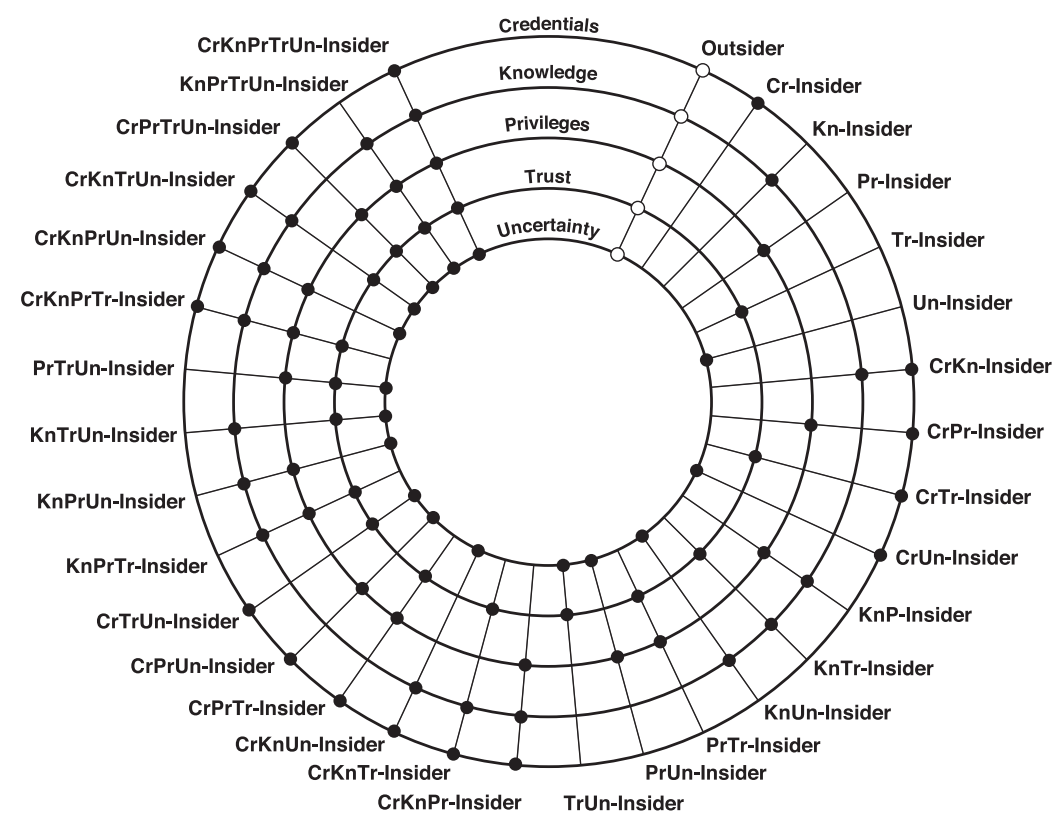

Fig. 2. An insider taxonomy of all combinations of insider types.

create synergies and increase the overall mitigation coverage. These implications for research and practice will be explained in more detail in Section 7.

\section{IMPLICATIONS FOR RESEARCHERS AND PRACTITIONERS}

The systematic foundations, as proposed in this article, serve two important goals. First, practitioners can now identify the insider types most relevant for their domain, either by modelling the insider types of real individuals or by modelling the insider types, which are potentially most threatening to their domain. Subsequently and equipped with unambiguous names of their insider types, they can then investigate specific properties as well as identify literature, which deals with exactly the same insider types. Second, the research field on insider threats gets structured in a way, so that researchers can speak the same language and compare their work only with other research, that is actually targeting the same insider. Additionally, certain threatening aspects of insiders, which can be backtracked and mapped to their distinct insider characteristics, can now be studied and dealt with separately according to the well established divide-and-conquer principle. The following sections elaborate on these implications for researchers and practitioners. To achieve and facilitate future extension and enhancement, the classification dataset of existing insider definitions, as discussed in Section 5.3, will be made publicly available. A simple and extensible semantic wiki for already registered and classified literature regarding specific insider types, as illustrated in Figure 3, will be developed and published for future extension and reference as well.

\subsection{Applying the new Foundations in the Research on Insider Threats}

The definition and assessment of insider threats goes beyond just defining and assessing the insider, as it has sometimes been done in the past $[8,16,22,48]$. An insider threat is not a threat of an insider, but more precisely a threat of an insider, where his insiderness is involved (intentionally or accidentally) and where this insiderness actually enables or compounds the threat. ${ }^{9}$ Take a Tr-Insider of a specific domain as an example, who is carrying

\footnotetext{
${ }^{9}$ For clarification, the intention of an insider is of no concern in this description. The description is comprising intentionally malicious, accidental, as well as intentionally good-natured insider threats. The new foundations proposed in this article can be used despite the
} 

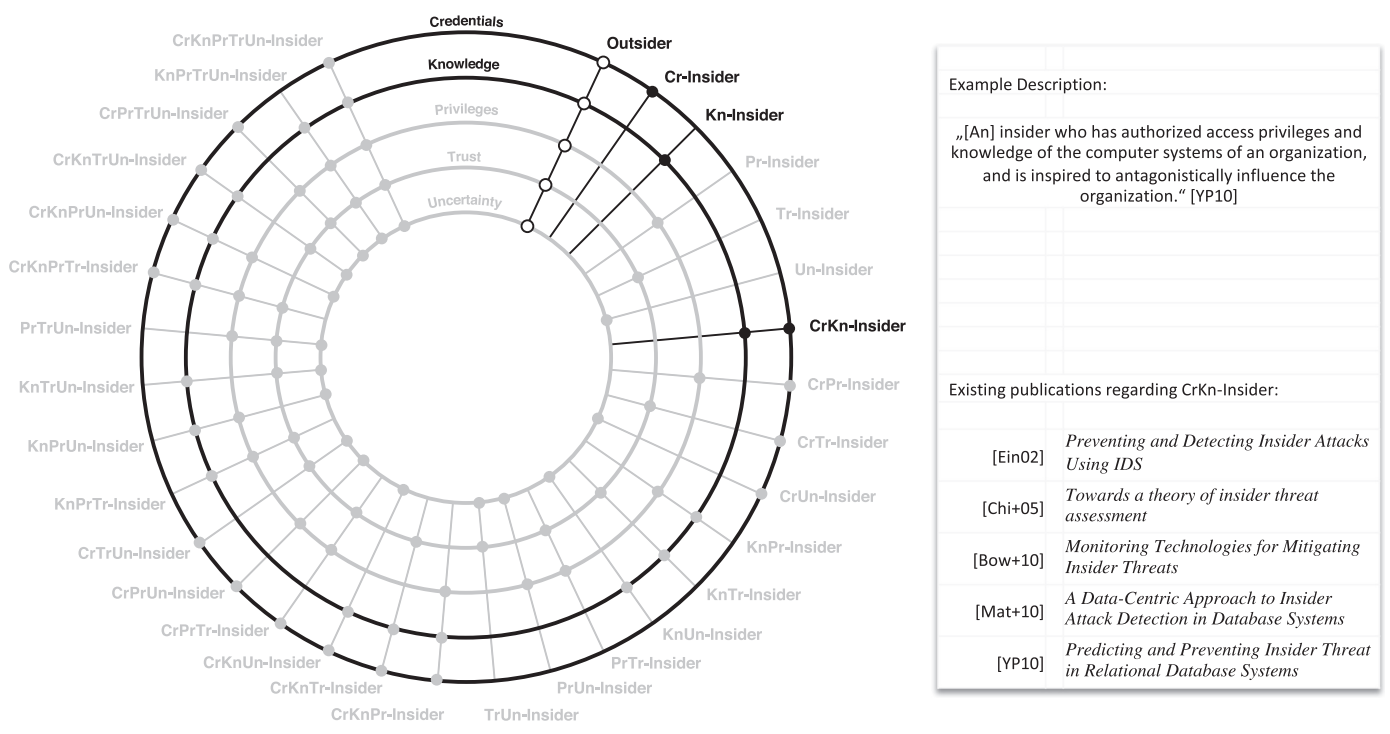

Fig. 3. Application of the insider taxonomy in conjunction with the classification of existing insider definitions.

out a successful brute-force attack on the access password of a member of that domain. This attack must not be considered as an insider attack, since the attacker could have brute-forced the password as successfully as without being a Tr-Insider. The insider ontology as proposed in this article is explicitly only focusing on the insiders themselves as well as their characteristics. Which means that it only covers the insiderness part of an insider threat assessment. So it allows to derive specific insider characteristics as well as their gradual level. What remains uncovered is the assessment of threat specific characteristics and the assessment of unmediated influences of insider characteristics on that threat. Finding out and dealing with these influencing factors might very likely prove itself vital in identifying as well as developing effective mitigation techniques against insider threats. The dissection of a specific insider threat into several distinct smaller problems is helping in this task. Knowing the insider characteristics, which are related to an insider threat, allows putting the focus on specific properties arising from each insider characteristic individually. This might not increase the understanding of complex insider threats right away. The interconnection of different insider characteristics probably still holds new threat properties, which might not be present for each insider characteristic individually. But it allows the application of the well-established divide-and-conquer principle, which certainly facilitates future positive progress in this research area.

Another important contribution of these systematic foundations for the field of research on insider threats reveals itself, when researcher propose new insights or a new technique for dealing with the threats of an insider. They can now unambiguously model the insider type, which they are focusing on. On the one hand, this serves as a guarantor that their research can be systematised and integrated into the dataset of already classified literature on insiders, as illustrated in Figure 3. It also allows the authors to talk to the community with a common language regarding the focus of their work. On the other hand, researchers can now identify actual related work, which is important to facilitate a meaningful comparison. Not only for the researchers themselves, but for the whole community as well, since this is crucial for judging the novelty and the effectiveness of new proposals. The mentioned dataset of already classified literature on insiders will be of help there as well.

$\overline{\text { different levels }}$ of intention, and they provide ways of dissecting the insider no matter if its actions are of malicious, non-malicious, or accidental nature (cf. Example 5.1 - Example 5.3). 


\subsection{Putting the Insider Taxonomy into Practice}

The proposed methodology of insider modelling in Section 5.2 provides practitioners with a universally applicable framework to identify the insiderness of actual individuals in their domain or of potentially threatening actors, who should be focused on when securing their environment. This not only enables the exchange of meaningful threat intelligence, but additionally, and equivalently to how researcher could benefit from this systematisation of existing literature, practitioners can now identify relevant publications, which target exactly the insider types of interest. Figure 3 shows an example, how this task can be supported by a simple semantic wiki, which provides ways to better understand the properties of insider types and additionally leads the way to related literature. The classification of existing publications in Section 5.3 serves as a bootstrap of this idea.

Once this fundamental systematisation reaches a point, where research on mitigation techniques of insider threats will be related to specific insider types as well (cf. Section 7.1), practitioners can identify suitable mitigation strategies. They even can compare different mitigation techniques, which target the same insider type, and combine mitigation techniques, which target different insider types to increase the overall coverage.

\section{CONCLUSION AND PROSPECTS}

The description of insiders and their domains is an integral part of research in the area of insider threats. This article demonstrated and resolved the lack of basic foundations and missing systematisations of these insider definitions. The central starting point in the formal and structured dissection of insider aspects is the identification of specific characteristics, which uniquely and solely qualify the insiderness of individuals. These comprise the membership to a domain (Credentials), the knowledge about insights of a domain (Knowledge), the allowed interactions with resources of a domain (Privileges), the degree of faith of a domain put into an individual to act truly, credibly, and honestly (Trust), as well as the structural trust (Uncertainty) (cf. Section 3). With these insider characteristics provided by a domain, basic insider types have been established, which can be combined in arbitrary ways and which describe every possible type of insider unambiguously (cf. Section 4 ). The numerical order of different suitable characteristic values, e.g., negligible, low, middle, and high, allows a gradual and precise description of an individual's degree of insiderness. As a result, there can be gradations between an outsider and an insider in each of the five dimensions represented by the insider characteristics. These findings were the basis to introduce insider models as well as a methodology to create insider models (cf. Section 5), which derive underlying insider types out of informal insider descriptions, scenarios, and definitions by explicitly naming an insider domain and by identifying and instantiating insider characteristics. With the help of example insider scenarios (cf. Section 5.1) as well as insider definitions of existing research publications (cf. Section 5.3), this procedure of insider modelling has been presented. One key finding was the fact that the main focus of the analysed research publications lies on the Cr-Insiders, Pr-Insiders, and CrPr-Insider. The proposed modelling methodology now allows the relation of insider descriptions and scenarios to research work, which focus on the same insider type(s). As a result, it becomes apparent, which research work deal with the same insider types and which scenarios are relevant for this research. The conducted analyses throughout this article attempt to bootstrap this endeavour. Additionally, relations between all possible insider types were presented and systematised via a simple insider taxonomy (cf. Section 6), so that future work on the analysis and systematisation of insider threats can build on it and identify explicit insider threats related to specific insider types as well as focus on basic mitigation techniques. All developed basic foundations taken together provide an insider ontology. In future work, this ontology facilitates accurate assertions about which detection and prevention mechanisms of insider threats can be compared with each other and which ones must be combined with each other to build a thorough level of protection against certain insider threat scenarios. 


\section{APPENDIX}

\section{A INSIDER MODELS AND INSIDER TYPES OF EXISTING INSIDER DEFINITIONS}

Listed below are the analysed 85 insider definitions, which have been extracted from 49 different scientific research publications, as well as the derived insider models and insider types.

\section{A.1 Anderson [3]}

Definition: "[T]he term "external penetration" is not confined to the usual case of an outsider attempting to access to a computer resource in an organization of which he is not a part. The term is meant to convey, in addition to the previous case, the notion of an employee of the organization who has physical access to the building housing the computer system but who is not an authorized computer user.'

Domain: The organisation

Insider Characteristics:

- Credentials: legitimate $\rightarrow \mathrm{Cr}_{\mathrm{A}}$-Insider

- Privileges: negligible $\rightarrow$ Pr-Outsider

Insider Type: $\mathrm{Cr}_{\mathrm{A}}$-Insider

Domain: A computer system

Insider Characteristics:

- Credentials: no $\rightarrow$ Cr-Outsider

Insider Type: Cr-Outsider

Definition: "He can be any category of individual; either an external penetrator ${ }^{10}$ who has succeeded in penetrating the installation access controls, [...]"

Domain: The organisation

Insider Characteristics:

- Credentials: legitimate $\rightarrow \mathrm{Cr}_{\mathrm{A}}$-Insider

- Privileges: low - high $\rightarrow$ Pr-Insider

Insider Type: $\mathrm{Cr}_{\mathrm{A}} \mathrm{Pr}$-Insider

Domain: A computer system

Insider Characteristics:

- Credentials: no $\rightarrow$ Cr-Outsider

- Privileges: low - high $\rightarrow$ Pr-Insider

Insider Type: Pr-Insider

Which means either a $\mathrm{Cr}_{\mathrm{A}}$ InsiderPrOutsider or a CrOutsider. See page 19.

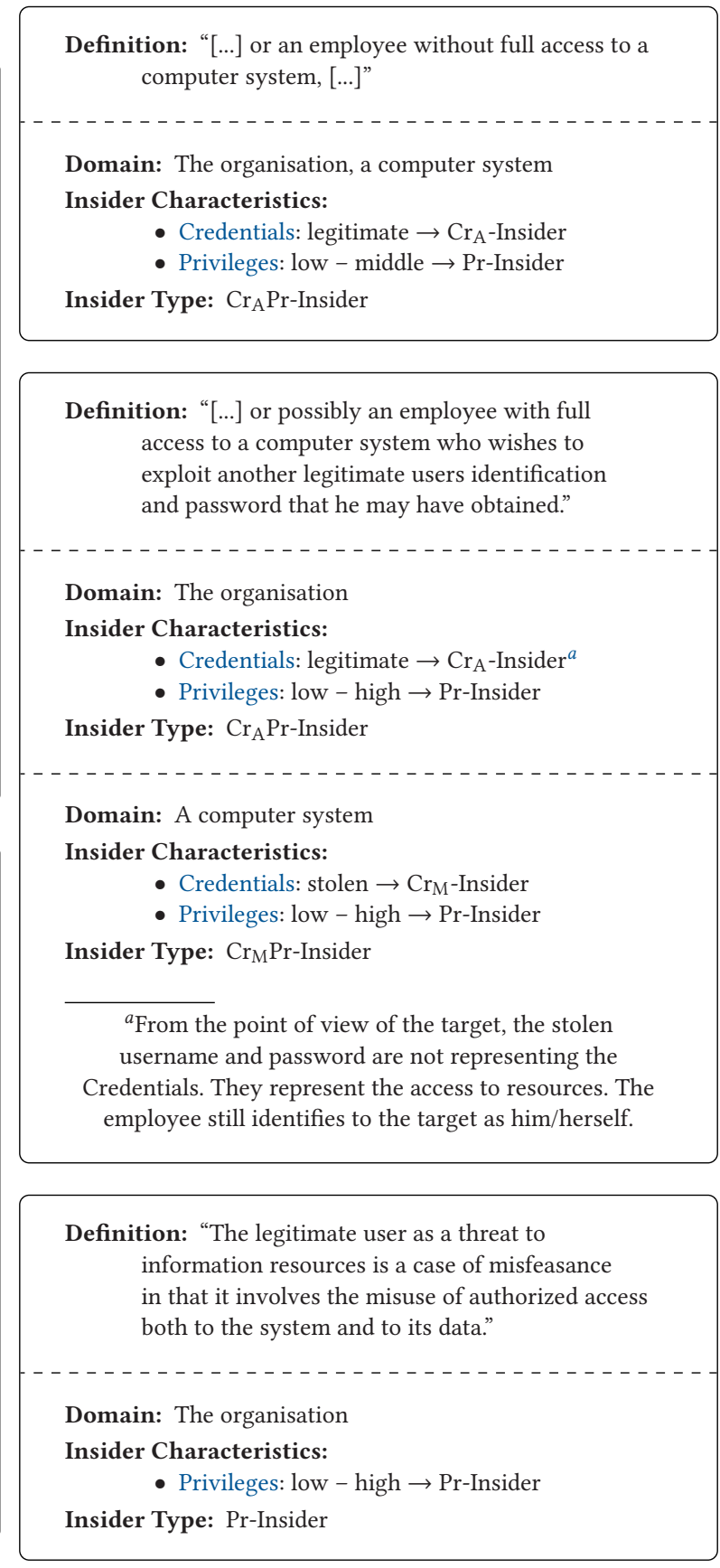




Domain: A computer system
Insider Characteristics:
- Credentials: legitimate $\rightarrow \mathrm{Cr}_{\mathrm{A}}$-Insider
- Privileges: low - high $\rightarrow$ Pr-Insider
Insider Type: $\mathrm{Cr}_{\mathrm{A}} \mathrm{Pr}-$ Insider

Definition: "The assumption regarding clandestine users is that the user has or can seize supervisory control of the machine and as such can either operate below the level at which audit trail data is taken or can use privileges or system primitives to evade audit trail data being recorded for him."

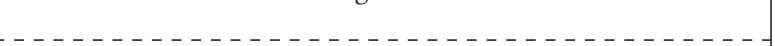

Domain: The organisation, a computer system Insider Characteristics:

- Credentials: legitimate $\rightarrow \mathrm{Cr}_{\mathrm{A}}$-Insider

- Privileges: high $\rightarrow$ Pr-Insider

- Uncertainty: high $\rightarrow$ Un-Insider

Insider Type: $\mathrm{Cr}_{\mathrm{A}}$ PrUn-Insider
${ }^{a}$ The context of this definition makes it clear, that a membership / authentication is assumed.

Definition: "A person with some sort of organizational status that causes members of the organization to view requests or demands as being authorized."

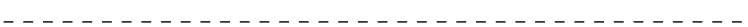

Domain: The organisation

Insider Characteristics:

- Trust: low-high $\rightarrow$ Tr-Insider

Insider Type: Tr-Insider

Definition: "A person with some level of privilege or authority with regard to the computer system."

Domain: The organisation

Insider Characteristics:

- Privileges: low - high $\rightarrow$ Pr-Insider

Insider Type: Pr-Insider

\section{A.2 Loch et al. [35]}

Definition: " $[\mathrm{A}]$ threat can be internal to the organization as the result of employee action [...]."

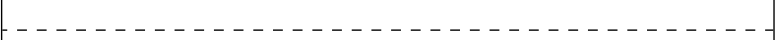

Domain: The organisation

Insider Characteristics:

- Credentials: legitimate $\rightarrow \mathrm{Cr}_{\mathrm{A}}$-Insider

Insider Type: $\mathrm{Cr}_{\mathrm{A}}$-Insider

\section{A.3 Committee on Information Systems Trustworthiness [13]}

Definition: "A person with legitimate physical access to computer equipment."

Domain: The organisation hosting the computer equipment

\section{Insider Characteristics:}

- Credentials: legitimate $\rightarrow \mathrm{Cr}_{\mathrm{A}}$-Insider ${ }^{a}$

- Privileges: low - high $\rightarrow$ Pr-Insider

Insider Type: $\mathrm{Cr}_{\mathrm{A}} \mathrm{Pr}$-Insider

\section{A.4 Neumann [45]}

Definition: "We assume that relative to a particular computational framework, insiders are users who have been authenticated to operate within that framework; where necessary, we qualify that to include reference to the authorized privileges that are associated with a particular authentication."

Domain: The computational framework

Insider Characteristics:

- Credentials: legitimate $\rightarrow \mathrm{Cr}_{\mathrm{A}}$-Insider

- Privileges: low - high $\vee$ negligible $\rightarrow \mathrm{Pr}$ Outsider $\vee$ Pr-Insider

Insider Type: $\mathrm{Cr}_{\mathrm{A}}$-Insider $\vee \mathrm{Cr}_{\mathrm{A}} \mathrm{Pr}$-Insider

\section{A.5 Lundin and Jonsson [36]}

Definition: "A masquerader can be defined as a person, either external or internal, who uses an account on the system for which he is not authorized."

Domain: A system

Insider Characteristics:

Digital Threats: Research and Practice, Vol. 3, No. 1, Article 2. Publication date: October 2021. 


• Credentials: stolen $\rightarrow \mathrm{Cr}_{\mathrm{M}}$-Insider
Insider Type: $\mathrm{Cr}_{\mathrm{M}}$-Insider
$\begin{aligned} & \text { Definition: "An insider is a legitimate user who misuses } \\ & \text { the system." }\end{aligned}$
Domain: A system
Insider Characteristics:
- Credentials: legitimate $\rightarrow \mathrm{Cr}_{\mathrm{A}}$-Insider
Insider Type: Cr ${ }_{\mathrm{A}}$-Insider

\section{A.6 Strunk et al. [59]}

Definition: "A successful intruder can obtain the rights
and identity of a legitimate user or administrator.
With these rights, it is possible to disrupt a system
by accessing, modifying, or destroying critical
data."
Domain: The organisation
Insider Characteristics:
- Credentials: stolen $\rightarrow \mathrm{Cr}_{\mathrm{M}}$-Insider
- Privileges: low $-\mathrm{high} \rightarrow$ Pr-Insider
Insider Type: $\mathrm{Cr}_{\mathrm{M}}$ Pr-Insider

\section{A.7 Einwechter [17]}

Definition: "Insider Attacks are an unusual type of threat. Unlike external attacks, the intruder is someone who has been entrusted with authorized access to the network. In fact, the attacker requires access to fulfil their obligations to the victim organization. Furthermore, they often have a substantial amount of knowledge about the network architecture, including where their targeted files or systems are located."

Domain: The network

Insider Characteristics:

- Credentials: legitimate $\rightarrow \mathrm{Cr}_{\mathrm{A}}$-Insider

- Knowledge: middle $\rightarrow$ Kn-Insider

Insider Type: $\mathrm{Cr}_{\mathrm{A}} \mathrm{Kn}$-Insider

\section{A.8 Schultz [54]}

Definition: "[Insiders are] those who are authorized to use computers and networks."

Domain: The organisation hosting the computers and networks

Insider Characteristics:

- Privileges: low - high $\rightarrow$ Pr-Insider

Insider Type: Pr-Insider

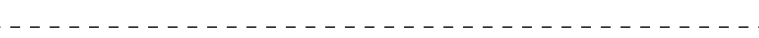

Domain: The computers and networks

Insider Characteristics:

- Credentials: stolen-legitimate $\rightarrow$ Cr-Insider

Insider Type: Cr-Insider

\section{A.9 Nguyen et al. [46]}

Definition: "Insiders represent the greatest threat to computer security because they understand their organization's business and how their computer systems work. They have both the confidentiality and access to perform these attacks. [...] The insiders also represent the greatest challenge to securing the company network because they are authorized a level of access to the file system and granted a degree of trust."

Domain: The organisation

Insider Characteristics:

- Knowledge: low-middle $\rightarrow$ Kn-Insider

- Privileges: low - high $\rightarrow$ Pr-Insider

- Trust: low-high $\rightarrow$ Tr-Insider

Insider Type: KnPrTr-Insider

\section{A.10 Patzakis [48]}

Definition: " $[M]$ any incident response teams fail to recognize and prepare for security compromises perpetrated by insiders. [...] As reflected by recent surveys, many incidents [...] are the work of rogue employees [...]"

Domain: Within the perimeter

Insider Characteristics:

- Credentials: legitimate $\rightarrow \mathrm{Cr}_{\mathrm{A}}$-Insider

Insider Type: $\mathrm{Cr}_{\mathrm{A}}$-Insider 


Definition: "[...] and other trusted individuals."
Domain: Within the perimeter
Insider Characteristics:
- Trust: low-high $\rightarrow$ Tr-Insider
Insider Type: Tr-Insider

\section{A.11 Spitzner [58]}

Definition: "[S]omeone who is technically skilled, highly motivated, and has access to extensive resources. For example, this threat may be an employee working for a large corporation, but in reality they are employed by a competitor to engage in corporate espionage. A second example is highly skilled, disgruntled employee motivated to cause a great deal of damage before they are fired. A third example could be a spy working for a foreign country. Regardless of who the insider is, we are dealing with a highly dangerous threat, one that is extremely difficult to detect. They have access to critical information; they know the structure of the organization."

Domain: The organisation

Insider Characteristics:

- Credentials: legitimate $\vee$ no $\rightarrow \mathrm{Cr}_{\mathrm{A}}$-Insider $\vee$ Cr-Outsider

- Knowledge: middle $\rightarrow$ Kn-Insider

- Privileges: high $\rightarrow$ Pr-Insider

Insider Type: $\mathrm{KnPr}$-Insider $\vee \mathrm{Cr}_{\mathrm{A}} \mathrm{KnPr}$-Insider

\section{A.12 Brackney and Anderson [8]}

$\begin{aligned} & \text { Definition: "An already trusted person with access to } \\ & \text { sensitive information and information systems." }\end{aligned}$
Domain: The organisation
Insider Characteristics:
- Privileges: middle $\rightarrow$ Pr-Insider
- Trust: low-high $\rightarrow$ Tr-Insider
Insider Type: PrTr-Insider
Domain: The information system
Insider Characteristics:
- Credentials: stolen-legitimate $\rightarrow$ Cr-Insider
- Trust: low-high $\rightarrow$ Tr-Insider

Insider Type: CrTr-Insider

Definition: "Someone with access [to information systems or services], [...]"

Domain: Information systems or services

Insider Characteristics:

- Credentials: stolen-legitimate $\rightarrow$ Cr-Insider

Insider Type: Cr-Insider

Definition: "[...] privileges [of information systems or services], [...]"

Domain: Information systems or services

Insider Characteristics:

- Privileges: low - high $\rightarrow$ Pr-Insider

Insider Type: Pr-Insider

Definition: "[...] or knowledge of information systems or services."

Domain: Information systems or services

Insider Characteristics:

- Knowledge: low-high $\rightarrow$ Kn-Insider

Insider Type: Kn-Insider

\section{A.13 Jha et al. [27]}

Definition: "[...] the masquerade-detection problem, which is defined as determining the identity of the user that generated a given execution trace."

Domain: Anything

Insider Characteristics:

- Credentials: stolen $\rightarrow \mathrm{Cr}_{\mathrm{M}}$-Insider

Insider Type: $\mathrm{Cr}_{\mathrm{M}}$-Insider

\section{A.14 Maxion and Townsend [41]}

Definition: "There are many ways for a masquerader to gain access to legitimate user accounts, e.g., through a purloined password or a hacker's break in. $[\ldots]$ "

$------------------------------$

Digital Threats: Research and Practice, Vol. 3, No. 1, Article 2. Publication date: October 2021. 


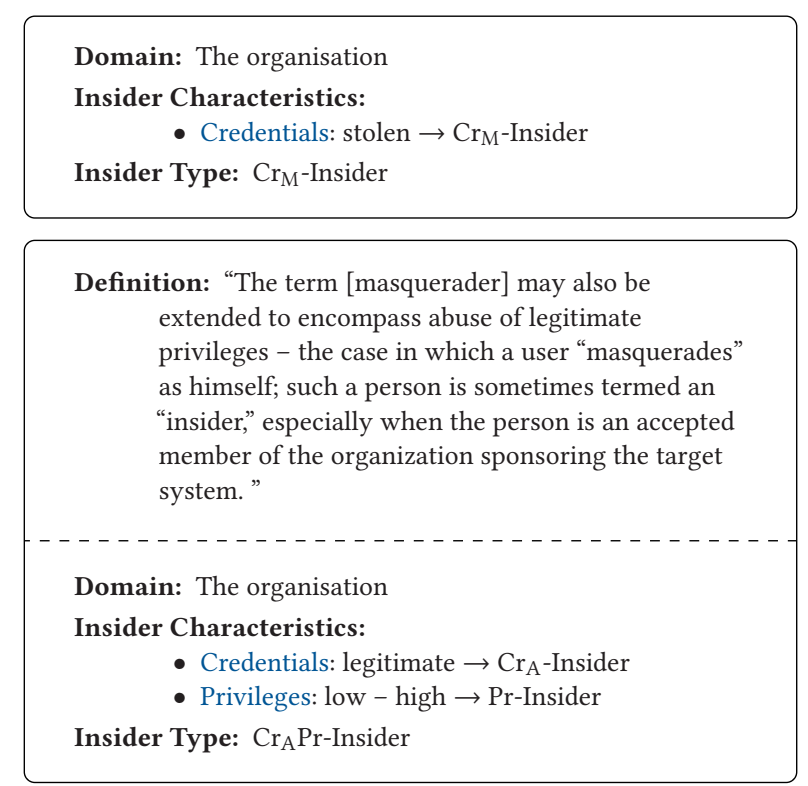

\section{A.15 Aleman-Meza et al. [2]}

Definition: "Insider Threat refers to the potential malevolent actions by employees within an organization, a specific type of which relates to legitimate access of documents."

Domain: The organisation

Insider Characteristics:

- Credentials: legitimate $\rightarrow \mathrm{Cr}_{\mathrm{A}}$-Insider

- Privileges: low - high $\rightarrow$ Pr-Insider

Insider Type: $\mathrm{Cr}_{\mathrm{A}}$-Insider $\vee \mathrm{Cr}_{\mathrm{A}} \mathrm{Pr}$-Insider

\section{A.16 Bishop [4]}

Definition: "An insider with respect to rules $\mathrm{R}$ is a user who may take action that would violate some set $\mathrm{R}$ of rules in the security policy were the user not trusted. The insider is trusted to take the action only when appropriate, as determined by the insider's discretion."

Domain: The system enforcing the rules $\mathrm{R}$

Insider Characteristics:

- Credentials: stolen-legitimate $\rightarrow$ Cr-Insider

- Privileges: low - high $\rightarrow$ Pr-Insider

- Trust: middle $\rightarrow$ Tr-Insider

Insider Type: CrPrTr-Insider

\section{A.17 Butts et al. [9]}

Definition: "Any individual who has been granted any level of trust in an information system."

Domain: The information system

Insider Characteristics:

- Trust: negligible $\vee$ low-high $\rightarrow$ Tr-Insider $\vee$ TrOutsider

Insider Type: Tr-Insider $\vee$ Tr-Outsider

\section{A.18 Chinchani et al. [11]}

Definition: "We assume that every legitimate user is an insider. [...] Insiders are in a unique position with the privileges entrusted to them and the knowledge about their computational environment [...]. They are a part of an organization and bound by the organization policy [...]."

- - - - - - - - - - - - - - - - - - - - - - - - - - - - - -

Domain: The organisation

Insider Characteristics:

- Credentials: legitimate $\rightarrow \mathrm{Cr}_{\mathrm{A}}$-Insider

- Knowledge: low-high $\rightarrow$ Kn-Insider

- Privileges: low - high $\rightarrow$ Pr-Insider

- Uncertainty: low $\rightarrow$ Un-Insider

Insider Type: $\mathrm{Cr}_{\mathrm{A}} \mathrm{KnPrUn}$-Insider

Definition: "External attackers can become insiders too by compromising an internal system and learning about the computers in the neighborhood."

Domain: The organisation

Insider Characteristics:

- Credentials: stolen $\rightarrow \mathrm{Cr}_{\mathrm{M}}$-Insider

- Knowledge: low-middle $\rightarrow$ Kn-Insider

Insider Type: $\mathrm{Cr}_{\mathrm{M}} \mathrm{Kn}$-Insider

\section{A.19 Cole and Ring [12]}

Definition: "Outside affiliates are non-trusted outsiders who use open access to gain access to an organization's resources [and have no legitimate reason to access the building]."

Domain: The organisation

Insider Characteristics: 
- Credentials: no $\rightarrow$ Cr-Outsider

- Privileges: low $\rightarrow$ Pr-Insider

- Trust: negligible $\rightarrow$ Tr-Outsider

Insider Type: Pr-Insider

Definition: "An insider affiliate is a spouse, friend, or even client of an employee who uses the employee's credentials to gain access [and has no legitimate reason to access the building]."

- - - - - - - - - - - - - - - - - - - - - - - - - - -

Domain: The organisation

Insider Characteristics:

- Credentials: stolen $\rightarrow \mathrm{Cr}_{M}$-Insider

Insider Type: $\mathrm{Cr}_{\mathrm{M}}$-Insider

Definition: "Insider associates are people who have limited authorized access [and have legitimate reason to access the building]. [. . . ] Limited access usually takes the form of having physical access to the facility but not access to the network."

- - - - - - - - - - - - - - - - - - - - - - - - - - -

Domain: The organisation

Insider Characteristics:

- Credentials: legitimate $\rightarrow \mathrm{Cr}_{\mathrm{A}}$-Insider

- Privileges: negligible $\rightarrow$ Pr-Outsider

Insider Type: $\mathrm{Cr}_{\mathrm{A}}$-Insider

Domain: The network

Insider Characteristics:

- Credentials: no $\rightarrow$ Cr-Outsider

Insider Type: Cr-Outsider

Definition: "A pure insider is an employee with all the rights and access associated with being employed by the company. Typically, they have keys or a badge to get access to the facility, a logon to get access to the network, and can walk around the building unescorted."

Domain: The organisation

Insider Characteristics:

- Credentials: legitimate $\rightarrow \mathrm{Cr}_{\mathrm{A}}$-Insider

- Privileges: low - high $\rightarrow$ Pr-Insider

Insider Type: $\mathrm{Cr}_{\mathrm{A}} \mathrm{Pr}$-Insider

Domain: The network
Insider Characteristics:

- Credentials: legitimate $\rightarrow \mathrm{Cr}_{\mathrm{A}}$-Insider

Insider Type: $\mathrm{Cr}_{\mathrm{A}}$-Insider

Definition: "Elevated pure insider is an [pure] insider who has additional privileged access. This usually includes system administrators who have root or administrator access on the network."

Domain: The organisation

Insider Characteristics:

- Credentials: legitimate $\rightarrow \mathrm{Cr}_{\mathrm{A}}$-Insider

- Privileges: high $\rightarrow$ Pr-Insider

Insider Type: $\mathrm{Cr}_{\mathrm{A}} \mathrm{Pr}$-Insider

Domain: The network

Insider Characteristics:

- Credentials: legitimate $\rightarrow \mathrm{Cr}_{\mathrm{A}}$-Insider

- Privileges: high $\rightarrow$ Pr-Insider

Insider Type: $\mathrm{Cr}_{\mathrm{A}} \mathrm{Pr}$-Insider

\section{A.20 Liu et al. [34]}

Definition: "The "insider threat" involves the actions of a trusted and privileged user who is inappropriately accessing or disseminating sensitive information or otherwise compromising information systems."

Domain: Information systems

Insider Characteristics:

- Privileges: low - high $\rightarrow$ Pr-Insider

- Trust: low-high $\rightarrow$ Tr-Insider

Insider Type: PrTr-Insider

Definition: "Insider threat refers to cases in which users who have legitimate access to a system abuse their privileges for purposes not related to their authorized use."

Domain: A system

Insider Characteristics:

- Credentials: legitimate $\rightarrow \mathrm{Cr}_{\mathrm{A}}$-Insider

- Privileges: low - high $\rightarrow$ Pr-Insider

Insider Type: $\mathrm{Cr}_{\mathrm{A}} \mathrm{Pr}$-Insider

Digital Threats: Research and Practice, Vol. 3, No. 1, Article 2. Publication date: October 2021. 


\section{A.21 Maybury et al. [42]}

Definition: "An insider as anyone in an organization with approved access, privilege, or knowledge of information systems, information services, and missions."

Domain: The organisation

Insider Characteristics:

- Credentials: legitimate $\rightarrow \mathrm{Cr}_{\mathrm{A}}$-Insider

- Privileges: low - high $\rightarrow$ Pr-Insider

- Knowledge: low-high $\rightarrow$ Kn-Insider

Insider Type: $\mathrm{Cr}_{\mathrm{A}}$-Insider $\vee \mathrm{Kn}$-Insider $\vee \mathrm{Pr}$-Insider

\section{A.24 Shirey [55]}

Definition: "An insider [is] an entity that is authorized
to access system resources but uses them in a
way not approved by the party that granted the
authorization."
Domain: A system
Insider Characteristics:
- Privileges: low - high $\rightarrow$ Pr-Insider
Insider Type: Pr-Insider

Definition: "A user (usually a person) that accesses a system from a position that is inside the system's security perimeter."

Domain: A system

Insider Characteristics:

- Credentials: stolen-legitimate $\rightarrow$ Cr-Insider

- Privileges: low - high $\rightarrow$ Pr-Insider

Insider Type: $\mathrm{Cr}$-Insider $\vee \mathrm{Pr}$-Insider

Domain: The network
Insider Characteristics:

- Privileges: middle $\rightarrow$ Pr-Insider

Insider Type: Pr-Insider

\section{A.25 Greitzer et al. [22]}

\section{A.23 Magklaras et al. [39]}

Definition: "An insider is a person that has been legitimately given the capability of accessing one or many components of the IT infrastructure, by interacting with one or more authentication mechanisms (plain text password, PKI, biometric or smart card token). [...] It also means that an insider is less likely to get caught by implemented security measures because of the level of trust that she enjoys."

Domain: The IT infrastructure Insider Characteristics:

- Credentials: legitimate $\rightarrow \mathrm{Cr}_{\mathrm{A}}$-Insider

- Privileges: low - high $\rightarrow$ Pr-Insider

- Uncertainty: middle $\rightarrow$ Un-Insider

Insider Type: $\mathrm{Cr}_{\mathrm{A}}$ PrUn-Insider 


\section{A.26 Kamra et al. [28]}

$\begin{aligned} & \text { Definition: "[S]ubjects that are legitimate users of the } \\ & \text { system, and thus may have access rights to data } \\ & \text { and resources. " }\end{aligned}$
Domain: A system
Insider Characteristics:
- Credentials: legitimate $\rightarrow \mathrm{Cr}_{\mathrm{A}}$-Insider
Privileges: low - high $\vee$ negligible $\rightarrow$ Pr-
Outsider $\vee$ Pr-Insider
Insider Type: $\mathrm{Cr}_{\mathrm{A}}$-Insider $\vee \mathrm{Cr}_{\mathrm{A}}$ Pr-Insider

\section{A.27 Pfleeger [49]}

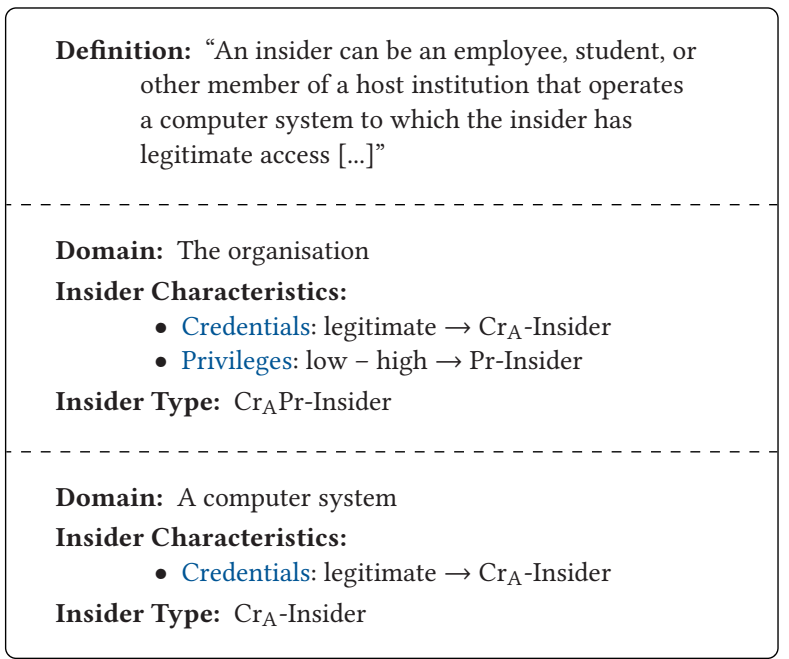

Domain: A system

Insider Characteristics:

- Privileges: low - high $\rightarrow$ Pr-Insider

Insider Type: Pr-Insider

Definition: “[... An insider can be] anyone properly identified and authenticated to the system including, perhaps, someone masquerading as a legitimate insider, or someone to whom an insider has given access (for example by sharing a password) [...]"

Domain: A system

Insider Characteristics:

- Credentials: stolen-legitimate $\rightarrow$ Cr-Insider

Insider Type: Cr-Insider

Definition: "[... An insider can be] someone duped or coerced by an outsider to perform actions on the outsider's behalf $[\ldots]$ ”

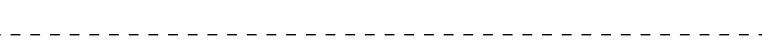

Domain: Anything

Insider Characteristics:

- Nothing mentioned

Insider Type: Outsider

Definition: "[... An insider can be] a former insider, now using previously conferred access credentials not revoked when the insider status ended or using access credentials secretly created while an insider to give access later."

Definition: "[... An insider can be] an associate, contractor, business partner, supplier, computer maintenance technician, guest, or someone else who has a formal or informal business relationship with the institution [...]"

Domain: The organisation

Insider Characteristics:

- Credentials: legitimate $\rightarrow \mathrm{Cr}_{\mathrm{A}}$-Insider

Insider Type: $\mathrm{Cr}_{\mathrm{A}}$-Insider

Definition: "[... An insider can be] anyone authorized to perform certain activities, for example a bank's customer who uses the bank's system to access his or her account [...]"

Domain: The former organisation

Insider Characteristics:

- Credentials: stolen $\rightarrow \mathrm{Cr}_{\mathrm{M}}$-Insider

Insider Type: $\mathrm{Cr}_{M}$-Insider

\section{A.28 Bishop et al. [6]}

Definition: " $[\mathrm{A}]$ security policy is inherently represented by the access control rules employed by an organization. So, an insider is defined with regard to two primitive actions: 1 . violation of a security policy using legitimate access, [...]"

Digital Threats: Research and Practice, Vol. 3, No. 1, Article 2. Publication date: October 2021. 
Domain: A system

Insider Characteristics:

- Credentials: stolen-legitimate $\rightarrow$ Cr-Insider

Insider Type: Cr-Insider

\section{A.31 Probst et al. [52]}

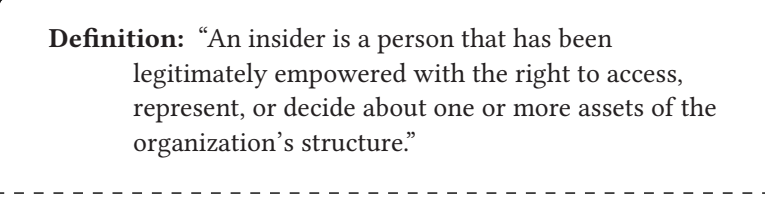

Domain: The organisation

Insider Characteristics:

- Privileges: low - high $\rightarrow$ Pr-Insider

Insider Type: Pr-Insider

\section{A.32 Bishop et al. [5]}

Definition: "Let $P_{L}$ and $P_{H}$ be representations of a policy at different levels of the Unifying Policy Hierarchy. If a subject has a different set of rights in $P_{L}$ than it has in $P_{H}$, it is called an insider. An insider attack occurs when an insider employs any rights that exist in $P_{L}$ and that do not exist in $P_{H}$."

Domain: A system

Insider Characteristics:

- Privileges: low - high $\rightarrow$ Pr-Insider

Insider Type: Pr-Insider
Definition: "We define insider threats by [...] Traitors (an inside attacker using their own legitimate credentials) who each have varying levels of knowledge."

Domain: Anything

Insider Characteristics:

- Credentials: legitimate $\rightarrow \mathrm{Cr}_{\mathrm{A}}$-Insider

- Knowledge: low-high $\vee$ negligible $\rightarrow \mathrm{Kn}$ Outsider $\vee$ Kn-Insider

Insider Type: $\mathrm{Cr}_{\mathrm{A}}$-Insider $\vee \mathrm{Cr}_{\mathrm{A}} \mathrm{Kn}$-Insider

\section{A.34 Greitzer and Frincke [21]}

Definition: "The "insider" is an individual currently or at one time authorized to access an organization's information system, data, or network; such authorization implies a degree of trust in the individual."

Domain: The organisation

Insider Characteristics:

- Privileges: low - high $\rightarrow$ Pr-Insider

- Trust: low-high $\rightarrow$ Tr-Insider

Insider Type: PrTr-Insider - - - - - - - - - - - - - - - - - - - - - - - - - -

Domain: Information system, data, or network Insider Characteristics:

- Credentials: legitimate $\vee$ no $\rightarrow \mathrm{Cr}_{\mathrm{A}}$-Insider $\vee$ Cr-Outsider

- Trust: low-high $\rightarrow$ Tr-Insider

- Knowledge: middle $\rightarrow$ Kn-Insider

Insider Type: $\mathrm{Cr}_{\mathrm{A}} \mathrm{Tr}$-Insider $\vee \mathrm{KnTr}$-Insider

\section{A.33 Bowen et al. [7]}

Definition: "We define insider threats by [...] Masqueraders (attackers who impersonate another inside user) [... and who are] presumed to have less knowledge of a system than the victim user [...]."

Domain: Anything

Insider Characteristics:

- Credentials: stolen $\rightarrow \mathrm{Cr}_{M}$-Insider

- Knowledge: negligible $\vee$ low-middle $\rightarrow$ KnOutsider $\vee$ Kn-Insider

Insider Type: $\mathrm{Cr}_{M} \mathrm{Kn}$-Insider $\vee \mathrm{Cr}_{M}$-Insider

\section{A.35 Cappelli et al. [10]}

Definition: "[An insider] is a current or former employee, contractor, or business partner who has or had authorized access to an organization's network, system, or data [...]"

Domain: The organisation

Insider Characteristics:

- Credentials: legitimate $\vee$ no $\rightarrow \mathrm{Cr}_{\mathrm{A}}$-Insider $\vee$ Cr-Outsider

- Privileges: low - high $\rightarrow$ Pr-Insider

Insider Type: Pr-Insider $\vee \mathrm{Cr}_{\mathrm{A}} \mathrm{Pr}$-Insider

Digital Threats: Research and Practice, Vol. 3, No. 1, Article 2. Publication date: October 2021. 


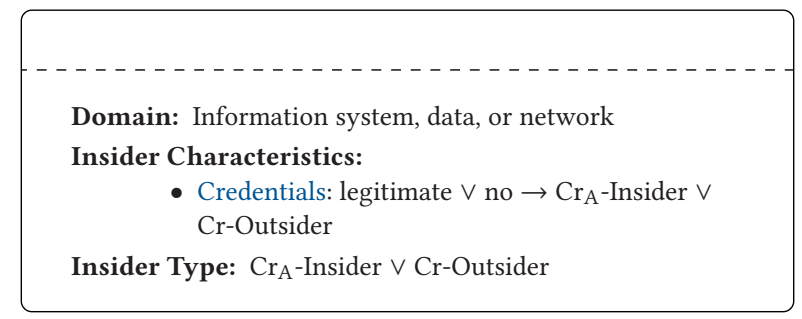

\section{A.36 Kandias et al. [29]}

Definition: "[A]n insider is a human entity that has/had
access to the information system of an organization
and does not comply with the security policy of the
organization."
Domain: The organisation
Insider Characteristics:
- Privileges: low - high $\rightarrow$ Pr-Insider
Insider Type: Pr-Insider
Domain: The information system
Insider Characteristics:
\[ \text { Credentials: stolen-legitimate } \rightarrow \text { Cr-Insider } \]
Insider Type: Cr-Insider
Insider Type: Kn-Insider
Insider Characteristics:
- Credentials: no $\rightarrow$ Cr-Outsider
Domain: The organisation; the information system
-

\section{A.37 Mathew et al. [40]}

Definition: "An insider is a database subject who has personal knowledge of information stored in one or more fields marked confidential."

Domain: The database

Insider Characteristics:

- Credentials: legitimate $\rightarrow \mathrm{Cr}_{\mathrm{A}}$-Insider

- Knowledge: low-middle $\rightarrow$ Kn-Insider

Insider Type: $\mathrm{Cr}_{\mathrm{A}} \mathrm{Kn}$-Insider

\section{A.38 Pfleeger et al. [50]}

Definition: “A person with legitimate access to an
organization's computers and networks."
Domain: The organisation
Insider Characteristics:
$\quad$ - Privileges: low - high $\rightarrow$ Pr-Insider
Insider Type: Pr-Insider
Domain: Information system, data, or network
Insider Characteristics:
$\quad$ Credentials: legitimate $\rightarrow \mathrm{Cr}_{\mathrm{A}}$-Insider
Insider Type: Cr${ }_{\mathrm{A}}$-Insider

\section{A.39 Yaseen and Panda [64]}

Definition: "It is defined as the threat that is caused by a malicious insider who has authorized access privileges and knowledge of the computer systems of an organization, and is inspired to antagonistically influence the organization."

Domain: The organisation

Insider Characteristics:

- Knowledge: low-high $\rightarrow$ Kn-Insider

- Privileges: low - high $\rightarrow$ Pr-Insider

Insider Type: KnPr-Insider

Domain: The computer systems

Insider Characteristics:

- Credentials: stolen-legitimate $\rightarrow$ Cr-Insider

- Knowledge: low-high $\rightarrow$ Kn-Insider

Insider Type: CrKn-Insider

\section{A.40 Hunker and Probst [25]}

Definition: " $[\mathrm{A}] \mathrm{n}$ insider is defined as an individual with privileged access to an IT system."

Domain: The information system

Insider Characteristics:

- Privileges: low - high $\rightarrow$ Pr-Insider

Insider Type: Pr-Insider 


Definition: "We would observe that in practice - at
least to the extent that we are able to observe real
incidents - the problem of real interest is the "real
real insider"; an individual deeply embedded in an
organization, highly trusted, and in a position to
do great damage if so inclined (e.g., a high level
executive, or a systems administrator)."
Domain: The organisation
Insider Characteristics:
- Credentials: legitimate $\rightarrow \mathrm{Cr}_{\mathrm{A}}$-Insider
- Privileges: high $\rightarrow$ Prust: high $\rightarrow$ Tr-Insider
Insider Type: $\mathrm{Cr}_{\mathrm{A}} \operatorname{PrTr}$-Insider

\section{A.41 Fuchs and Pernul [18]}

Definition: "Insider threats represent the historical cause
of the majority of incidents with the authorized,
non-technical employee being the typical potential
threat to Information Security"
Domain: The organisation
Insider Characteristics:
- Credentials: legitimate $\rightarrow \mathrm{Cr}_{\mathrm{A}}$-Insider
- Privileges: low - high $\rightarrow \mathrm{Pr}$-Insider
Insider Type: $\mathrm{Cr}_{\mathrm{A}}$ Pr-Insider

Definition: "[I]ndividuals that have a trusted relationship with organizations - namely (former) employees, contractors, or consultants - represent a typical potential threat for Information Security. Those authorized non-technical insiders directly interact with an organization's Information Systems, have some type of authority on those systems, and know about security processes and how to circumvent them."

- - - - - - - - - - - - - - - - - - - - - - - - - - - - - - - -

Domain: The organisation

Insider Characteristics:

- Credentials: legitimate $\vee$ no $\rightarrow \mathrm{Cr}_{\mathrm{A}}$-Insider $\vee$ Cr-Outsider

- Knowledge: low-high $\rightarrow$ Kn-Insider

- Privileges: low - high $\rightarrow$ Pr-Insider

- Trust: low-high $\rightarrow$ Tr-Insider

- Uncertainty: low-high $\rightarrow$ Un-Insider

Insider Type: KnPrTrUn-Insider $\vee \mathrm{Cr}_{\mathrm{A}} \mathrm{KnPrTrUn}$-Insider

\section{A.42 Kissel [32]}

Definition: "An entity with authorized access (i.e., within the security domain) that has the potential to harm an information system or enterprise through destruction, disclosure, modification of data, and/or denial of service."

Domain: Security domain (e.g., an information system or enterprise)

Insider Characteristics:

- Credentials: stolen-legitimate $\rightarrow$ Cr-Insider

Insider Type: Cr-Insider

\section{A.43 Vickers [61]}

Definition: "Anyone who has authorized access to [Department of Defence (DoD)] resources by virtue of employment, volunteer activities, or contractual relationship with DoD."

Domain: The organisation

Insider Characteristics:

- Credentials: legitimate $\rightarrow \mathrm{Cr}_{\mathrm{A}}$-Insider

- Privileges: low - high $\rightarrow$ Pr-Insider

Insider Type: $\mathrm{Cr}_{\mathrm{A}} \mathrm{Pr}$-Insider

Definition: "A person with authorized access, who uses that access, wittingly or unwittingly, to harm national security interests or national security through unauthorized disclosure, data modification, espionage, terrorism, or kinetic actions resulting in loss or degradation of resources or capabilities."

Domain: Anything

Insider Characteristics:

- Privileges: low - high $\rightarrow$ Pr-Insider

Insider Type: Pr-Insider

Definition: "A person, known or suspected, who uses their authorized access to DoD facilities, personnel, systems, equipment, information, or infrastructure to damage and disrupt operations, compromise DoD information, or commit espionage on behalf of an [Foreign Intelligence Entity].”

Domain: DoD facilities, personnel, systems, equipment, information, or infrastructure 
Insider Characteristics:

- Credentials: stolen-legitimate $\rightarrow$ Cr-Insider

Insider Type: Cr-Insider

\section{A.44 Kaplan et al. [30]}

Definition: "The errant insider is unaware of security protocols, ignores cybersecurity policies or simply commits errors resulting in sensitive data being compromised or networks becoming vulnerable."

Domain: Anything

Insider Characteristics:

- Knowledge: negligible $\rightarrow$ Kn-Outsider

Insider Type: Kn-Outsider

Definition: "The hijacked insider has their credentials compromised by someone externally, giving the outsider the same level of access as the insider."

Domain: Anything

Insider Characteristics:

- Credentials: stolen $\rightarrow \mathrm{Cr}_{M}$-Insider

- Privileges: low - high $\rightarrow$ Pr-Insider

Insider Type: $\mathrm{Cr}_{M} \mathrm{Pr}$-Insider

Definition: "Finally, the malevolent insider is willing to steal or compromise data for personal gain."

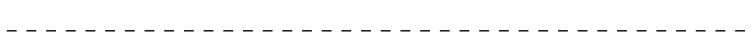

Domain: Anything

Insider Characteristics:

- Nothing mentioned

Insider Type: Outsider

\section{A.45 McGough et al. [44]}

Definition: "An insider threat can be defined as [...]: the intent to inflict harm by one who has special knowledge or access to confidential information."

Domain: Anything

Insider Characteristics:

- Knowledge: low-high $\rightarrow$ Kn-Insider

- Privileges: low - high $\rightarrow$ Pr-Insider

Insider Type: Pr-Insider $\vee$ Kn-Insider

\section{A.46 Maasberg et al. [37]}

Definition: "Insiders have unique access to information systems. [...] Compared to an outsider, insiders typically have some level of access, authorization, and/or advanced organizational knowledge."

Domain: The organisation

Insider Characteristics:

- Privileges: low - high $\rightarrow$ Pr-Insider

- Credentials: stolen-legitimate $\rightarrow \mathrm{Cr}$-Insider

- Knowledge: low-high $\vee$ high $\rightarrow$ Kn-Insider

Insider Type: $\mathrm{Kn}$-Insider $\vee \mathrm{Cr}$-Insider $\vee \mathrm{CrKnPr}$-Insider $\vee$ Pr-Insider

Definition: "The insider threat occurs when trusted members of an organization "behave in ways that put our data, our systems, our organizations, and even our businesses' viability at risk"."

Domain: The organisation

Insider Characteristics:

- Credentials: legitimate $\rightarrow \mathrm{Cr}_{\mathrm{A}}$-Insider

- Trust: low-high $\rightarrow$ Tr-Insider

Insider Type: $\mathrm{Cr}_{\mathrm{A}} \mathrm{Tr}$-Insider

\section{A.47 Costa [14]}

Definition: "[A]n individual who has or had authorized access to an organization's assets $[\ldots]$."

Domain: The organisation

Insider Characteristics:

- Privileges: low - high $\rightarrow$ Pr-Insider

Insider Type: Pr-Insider

Domain: The organisation's assets

Insider Characteristics:

- Credentials: legitimate $\vee$ no $\rightarrow \mathrm{Cr}_{\mathrm{A}}$-Insider $\vee$ Cr-Outsider

Insider Type: $\mathrm{Cr}_{\mathrm{A}}$-Insider $\vee \mathrm{Cr}$-Outsider 


\section{A.48 Shulman et al. [56]}

Definition: "Embodiments of the invention provide for methods, systems, and apparatuses using reverse honey tokens to enable a "compromised insider" production honeypot and thereby detect if an intruder has compromised a client end station in an attempt to gain unauthorized access to enterprise data of one or more servers."

Domain: The organisation

Insider Characteristics:

- Credentials: no $\rightarrow$ Cr-Outsider

- Privileges: low - high $\rightarrow$ Pr-Insider

Insider Type: Pr-Insider

\section{A.49 Khandelwal [31]}

Definition: "FIO (foreign intelligence officers) actors [who can steal documents]."

- - - - - - - - - - - - - - - - - - - - - - - - - - - - -

Domain: Anything

Insider Characteristics:

- Privileges: low - high $\rightarrow$ Pr-Insider

Insider Type: Pr-Insider 


\section{REFERENCES}

[1] Christian W. Probst, Jeffrey Hunker, Dieter Gollmann, and Matt Bishop (Eds.). 2010. Insider Threats in Cyber Security. Advances in Information Security, Vol. 49. Springer US. https://doi.org/10.1007/978-1-4419-7133-3_1

[2] Boanerges Aleman-Meza, Phillip Burns, Matthew Eavenson, Devanand Palaniswami, and Amit Sheth. 2005. An ontological approach to the document access problem of insider threat. In Intelligence and Security Informatics, Paul Kantor, Gheorghe Muresan, Fred Roberts, Daniel D. Zeng, Fei-Yue Wang, Hsinchun Chen, and Ralph C. Merkle (Eds.). Springer, Berlin, 486-491. https://link.springer.com/chapter/ 10.1007/11427995_47.

[3] J. P. Anderson. 1980. Computer Security Threat Monitoring and Surveillance. Technical Report. James P. Anderson Co., Fort Washington, PA. Retrieved from http://csrc.nist.gov/publications/history/ande80.pdf.

[4] Matt Bishop. 2005. Position: "Insider" is relative. In Proceedings of the 2005 Workshop on New Security Paradigms (NSPW'05), Christian F. Hempelmann and Victor Raskin (Eds.). ACM, New York, NY, 77-78. https://doi.org/10.1145/1146269.1146288

[5] Matt Bishop, Sophie Engle, Deborah A. Frincke, Carrie Gates, Frank L. Greitzer, Sean Peisert, and Sean Whalen. 2010. A Risk Management Approach to the "Insider Threat." 115-137. Volume 49 of Probst et al. [1]. https://doi.org/10.1007/978-1-4419-7133-3_1

[6] Matt Bishop, Sophie Engle, Sean Peisert, Sean Whalen, and Carrie Gates. 2009-01. Case studies of an insider framework. In Proceedings of the 42nd Hawaii International Conference on System Sciences (HICSS’09). 1-10. https://doi.org/10.1109/HICSS.2009.104

[7] Brian M. Bowen, Malek Ben Salem, Angelos D. Keromytis, and Salvatore J. Stolfo. 2010. Monitoring technologies for mitigating insider threats. See [1], 197-217. https://doi.org/10.1007/978-1-4419-7133-3_1

[8] Richard Brackney and Robert H. Anderson (Eds.). 2004. Understanding the Insider Threat. RAND Corporation, Santa Monica, CA.

[9] Jonathan W. Butts, Robert F. Mills, and Rusty O. Baldwin. 2005. Developing an insider threat model using functional decomposition. In Proceedings of the 3rd International Workshop on Mathematical Methods, Models, and Architectures for Computer Network Security (MMMACNS'05), Vladimir Gorodetsky, Igor Kotenko, and Victor Skormin (Eds.). Springer, Berlin, 412-417. https://doi.org/10.1007/11560326_32

[10] Dawn Cappelli, Andrew Moore, and Randall Trzeciak. 2012. The CERT Guide to Insider Threats: How to Prevent, Detect, and Respond to Information Technology Crimes (Theft, Sabotage, Fraud). Addison-Wesley Professional.

[11] R. Chinchani, A. Iyer, H. Q. Ngo, and S. Upadhyaya. 2005-06. Towards a theory of insider threat assessment. In Proceedings of the International Conference on Dependable Systems and Networks (DSN'05). 108-117. https://doi.org/10.1109/DSN.2005.94

[12] Eric Cole and Sandra Ring. 2005. Insider Threat: Protecting the Enterprise from Sabotage, Spying, and Theft. Elsevier.

[13] Committee on Information Systems Trustworthiness. 1998. Trust in Cyberspace. National Academy Press.

[14] Daniel Costa. 2017-03-07. CERT Definition of'Insider Threat'-Updated. Carnegie Mellon University's Software Engineering Institute Blog. Retrieved from http://insights.sei.cmu.edu/blog/cert-definition-of-insider-threat-updated/.

[15] Daniel Costa, Matthew Collins, Samuel J. Perl, Michael Albrethsen, George Silowash, and Derrick Spooner. 2014. An ontology for insider threat indicators: Development and application. In Proceedings of the 9th Conference on Semantic Technology for Intelligence, Defense, and Security (CEUR Workshop Proceedings, Vol. 1304), Kathryn Blackmond Laskey, Ian Emmons, and Paulo C. G. Costa (Eds.). 48-53.

[16] G. Doss and G. Tejay. 2009-06. Developing insider attack detection model: A grounded approach. In 2009 Proceedings of the IEEE International Conference on Intelligence and Security Informatics. 107-112.

[17] Nathan Einwechter. 2002-03. Preventing and detecting insider attacks using IDS. SecurityFocus (2002-03).

[18] Ludwig Fuchs and Günther Pernul. 2012. Minimizing insider misuse through secure Identity Management. Secur. Commun. Netw. 5, 8 (2012), 847-862. https://doi.org/10.1002/sec.314

[19] Fausto Giunchiglia and Ilya Zaihrayeu. 2009. Lightweight Ontologies. Springer US, Boston, MA, 1613-1619. https://doi.org/10.1007/9780-387-39940-9_1314

[20] Frank Greitzer, Justin Purl, Yung Mei Leong, and D. E. Sunny Becker. 2018. SOFIT: Sociotechnical and organizational factors for insider threat. In Proceedings of the IEEE Security and Privacy Workshops (SPW'18). 197-206. https://doi.org/10.1109/SPW.2018.00035

[21] Frank L. Greitzer and Deborah A. Frincke. 2010. Combining traditional cyber security audit data with psychosocial data: Towards predictive modeling for insider threat mitigation. See [1], 85-113. https://doi.org/10.1007/978-1-4419-7133-3_1

[22] F. L. Greitzer, A. P. Moore, D. M. Cappelli, D. H. Andrews, L. A. Carroll, and T. D. Hull. 2008-01. Combating the insider cyber threat. IEEE Secur. Priv. 6, 1 (2008-01), 61-64. https://doi.org/10.1109/MSP.2008.8

[23] Frank L. Greitzer, Jeremy R. Strozer, Sholom Cohen, Andrew P. Moore, David Mundie, and Jennifer Cowley. 2014-05. Analysis of unintentional insider threats deriving from social engineering exploits. In Proceedings of the IEEE Security and Privacy Workshops. 236250. https://doi.org/10.1109/SPW.2014.39

[24] Tom Gruber. 2009. Ontology. Springer US, Boston, MA, 1963-1965. https://doi.org/10.1007/978-0-387-39940-9_1318

[25] Jeffrey Hunker and Christian W. Probst. 2011. Insiders and insider threats-An overview of definitions and mitigation techniques. $\mathcal{F}$. Wireless Mobile Netw. Ubiq. Comput. Depend. Appl. 2, 1 (2011), 4-27. http://citeseerx.ist.psu.edu/viewdoc/summary?doi=10.1.1.465.7490.

[26] Vinay M. Igure and Ronald D. Williams. 2008-01. Taxonomies of attacks and vulnerabilities in computer systems. IEEE Commun. Surv. Tutor. 10, 1 (2008-01), 6-19. https://doi.org/10.1109/COMST.2008.4483667

[27] S. Jha, L. Kruger, T. Kurtx, Y. Lee, and A. Smith. 2004. A Filtering Approach to Anomaly and Masquerade Detection. Technical Report. Citeseer. Retrieved from http://citeseerx.ist.psu.edu/viewdoc/summary?doi=10.1.1.92.2211. 
[28] Ashish Kamra, Evimaria Terzi, and Elisa Bertino. 2008-08. Detecting anomalous access patterns in relational databases. VLDB f. 17, 5 (2008-08), 1063-1077. https://doi.org/10.1007/s00778-007-0051-4

[29] Miltiadis Kandias, Alexios Mylonas, Nikos Virvilis, Marianthi Theoharidou, and Dimitris Gritzalis. 2010. An insider threat prediction model. In Trust, Privacy and Security in Digital Business, Sokratis Katsikas, Javier Lopez, and Miguel Soriano (Eds.). Lecture Notes in Computer Science, Vol. 6264. Springer, Berlin, 26-37. https://doi.org/10.1007/978-3-642-15152-1_3

[30] James M. Kaplan, Tucker Bailey, Derek O’Halloran, Alan Marcus, and Rezek Chris. 2015. Beyond Cybersecurity: Protecting Your Digital Business. John Wiley \& Sons.

[31] Swati Khandelwal. 2017. Source Code for CIA's Tool to Track Whistleblowers Leaked by Wikileaks. Retrieved from https:// thehackernews.com/2017/04/wikiLeaks-scribbles-cia-whistleblower.html.

[32] Richard Kissel. 2013. NISTIR 7298-Glossary of Key Information Security Terms. Retrieved from https://doi.org/10.6028/NIST.IR.7298r2. Rev. 2.

[33] Ross Koppel, Tosha Wetterneck, Joel Leon Telles, and Ben-Tzion Karsh. 2008-07. Workarounds to barcode medication administration systems: Their occurrences, causes, and threats to patient safety. F. Am. Med. Inf. Assoc. 15, 4 (2008-07), 408-423.

[34] A. Liu, C. Martin, T. Hetherington, and S. Matzner. 2005-06. A comparison of system call feature representations for insider threat detection. In Proceedings of the 6th Annual IEEE SMC Information Assurance Workshop. 340-347. https://doi.org/10.1109/IAW.2005. 1495972

[35] Karen D. Loch, Houston H. Carr, and Merrill E. Warkentin. [n.d.]. Threats to information systems: Today's reality, yesterday's understanding. MIS Quart.

[36] Emilie Lundin and Erland Jonsson. 2000. Anomaly-based intrusion detection: Privacy concerns and other problems. Comput. Netw. 34, 4 (2000), 623-640. https://doi.org/10.1016/S1389-1286(00)00134-1

[37] M. Maasberg, J. Warren, and N. L. Beebe. 2015-01. The dark side of the insider: Detecting the insider threat through examination of dark triad personality traits. In Proceedings of the 48th Hawaii International Conference on System Sciences (HICSS'15). 3518-3526. https://doi.org/10.1109/HICSS.2015.423

[38] G. B. Magklaras and S. M. Furnell. 2001. Insider threat prediction tool: Evaluating the probability of IT misuse. Comput. Secur. 21, 1 (2001), 62-73. https://doi.org/10.1016/S0167-4048(02)00109-8

[39] G. B. Magklaras, S. M. Furnell, and P. J. Brooke. 2006. Towards an insider threat prediction specification language. Inf. Manage. Comput. Secur. 14, 4 (2006), 361-381. https://doi.org/10.1108/09685220610690826

[40] Sunu Mathew, Michalis Petropoulos, Hung Q. Ngo, and Shambhu Upadhyaya. 2010. A Data-Centric Approach to Insider Attack Detection in Database Systems. Springer, Berlin, 382-401. https://doi.org/10.1007/978-3-642-15512-3_20

[41] R. A. Maxion and T. N. Townsend. 2004-03. Masquerade detection augmented with error analysis. Trans. Reliabil. 53, 1 (2004-03), 124-147. https://doi.org/10.1109/TR.2004.824828

[42] Mark Maybury, Penny Chase, Brant Cheikes, Dick Brackney, Sara Matzner, Tom Hetherington, Brad Wood, Conner Sibley, Jack Marin, and Tom Longstaff. 2005. Analysis and Detection of Malicious Insiders. Technical Report. DTIC Document. Retrieved from https://www. researchgate.net/publication/228617716_Analysis_and_detection_of_malicious_insiders.

[43] Philipp Mayring. 2014. Qualitative Content Analysis: Theoretical Foundation, Basic Procedures and Software Solution. Klagenfurt.

[44] Andrew Stephen McGough, Budi Arief, Carl Gamble, David Wall, John Brennan, John Fitzgerald, Aad van Moorsel, Sujeewa Alwis, Georgios Theodoropoulos, and Ed Ruck-Keene. 2015-12. Detecting insider threats using ben-ware: Beneficial intelligent software for identifying anomalous human behaviour. F. Wireless Mobile Netw. Ubiq. Comput. Depend. Appl. 6, 4 (2015-12), 3-46. http://kar.kent.ac. $\mathrm{uk} / 54143 /$.

[45] Peter Neumann. 1999. The challenges of insider misuse.

[46] N. Nguyen, P. Reiher, and G. H. Kuenning. 2003-06. Detecting insider threats by monitoring system call activity. In Proceedings of the IEEE Systems, Man and Cybernetics Society Information Assurance Workshop. 45-52. https://doi.org/10.1109/SMCSIA.2003.1232400

[47] Peng Ning and Kun Sun. 2005. How to misuse AODV: A case study of insider attacks against mobile Ad-hoc routing protocols. Ad Hoc Netw. 3, 6 (2005), 795-819. https://doi.org/10.1016/j.adhoc.2004.04.001

[48] J. Patzakis. 2003. New Incident Response Best Practices: Patch and Proceed Is No Longer Acceptable Incident Response. Guidance Software, Pasadena, CA, Technical Report.

[49] Charles P. Pfleeger. 2008. Reflections on the insider threat. In Insider Attack and Cyber Security: Beyond the Hacker, Salvatore J. Stolfo, Steven M. Bellovin, Angelos D. Keromytis, Shlomo Hershkop, Sean W. Smith, and Sara Sinclair (Eds.). Springer US, Boston, MA, 5-16. https://doi.org/10.1007/978-0-387-77322-3

[50] S. L. Pfleeger, J. B. Predd, J. Hunker, and C. Bulford. 2010-03. Insiders behaving badly: Addressing bad actors and their actions. IEEE Trans. Inf. Forens. Secur. 5, 1 (2010-03), 169-179. https://doi.org/10.1109/TIFS.2009.2039591

[51] S. L. Pfleeger and S. J. Stolfo. 2009-11. Addressing the insider threat. IEEE Secur. Priv. 7, 6 (2009-11), 10-13. https://doi.org/10.1109/MSP. 2009.146

[52] Christian W. Probst, Jeffrey Hunker, Dieter Gollmann, and Matt Bishop. 2010. Aspects of insider threats. See [1], 1-15. https://doi.org/ 10.1007/978-1-4419-7133-3_1

Digital Threats: Research and Practice, Vol. 3, No. 1, Article 2. Publication date: October 2021. 
[53] Matthias Schonlau, William DuMouchel, Wen-Hua Ju, Alan F. Karr, Martin Theus, and Yehuda Vardi. 2001. Computer intrusion: Detecting masquerades. Statist. Sci. 16, 1 (2001), 58-74.

[54] E. Eugene Schultz. 2002. A framework for understanding and predicting insider attacks. Comput. Secur. 21, 6 (2002), 526-531. https: //doi.org/10.1016/S0167-4048(02)01009-X

[55] Robert W. Shirey. 2007-08. RFC4949-Internet Security Glossary (Version 2). Retrieved from https://tools.ietf.org/html/rfc4949.

[56] Amichai Shulman, Michael Cherny, and Sagie Dulce. 2017-05-30. Compromised Insider Honey Pots Using Reverse Honey Tokens. Retrieved from https://patents.google.com/patent/US9667651B2/en.

[57] Lance Spitzner. 2003-07-17. Honeytokens: The Other Honeypot. Retrieved from https://community.broadcom.com/symantecenterprise/ communities/community-home/librarydocuments/viewdocument?DocumentKey=74450cf5-2f11-48c5-8d92-4687f5978988.

[58] Lance Spitzner. 2003. Honeypots: Catching the insider threat. In Proceedings of the 19th Computer Security Applications Conference. IEEE Computer Society, 170-179. https://doi.org/10.1109/CSAC.2003.1254322

[59] John D. Strunk, Garth R. Goodson, Michael L. Scheinholtz, Craig A. N. Soules, and Gregory R. Ganger. 2000. Self-securing storage: Protecting data in compromised system. In Proceedings of the 4th Conference on Symposium on Operating System Design \& Implementation (OSDI’00, Vol. 4). USENIX Association, Berkeley, CA.

[60] T. Tuglular. 2000. A preliminary structural approach to insider computer misuse incidents. In Proceedings of the 1st European AntiMalware Conference (EICAR'00).

[61] Michael J. Vickers. 2013-10. Department of Defense Instruction: Countering Espionage, International Terrorism, and the Counterintelligence (CI) Insider Threat. Retrieved from https://www.hsdl.org/?view\&did=745624.

[62] Dustin Volz and Byron Tau. 2019-10-08. FBI's Use of Surveillance Database Violated Americans' Privacy Rights, Court Found. Online News. Retrieved from https://www.wsj.com/articles/fbis-use-of-foreign-surveillance-tool-violated-americans-privacy-rightscourt-found-11570559882.

[63] Bradley Wood. [n.d.]. An insider threat model for adversary simulation. 41-48.

[64] Qussai Yaseen and Brajendra Panda. 2010. Predicting and Preventing Insider Threat in Relational Database Systems. Springer, Berlin, 368-383. https://doi.org/10.1007/978-3-642-12368-9 30

Received October 2020; revised May 2021; accepted July 2021 